University of South Florida

DIGITAL COMMONS

Digital Commons @ University of

@ UNIVERSITY OF SOUTH FLORIDA

South Florida

November 2017

\title{
Capturing Resilience in Context: Development and Validation of a Situational Judgment Test of Resilience
}

\author{
Yuejia Teng \\ University of South Florida, tengyuejia@gmail.com
}

Follow this and additional works at: https://digitalcommons.usf.edu/etd

Part of the Personality and Social Contexts Commons

\section{Scholar Commons Citation}

Teng, Yuejia, "Capturing Resilience in Context: Development and Validation of a Situational Judgment Test of Resilience" (2017). USF Tampa Graduate Theses and Dissertations.

https://digitalcommons.usf.edu/etd/7098

This Thesis is brought to you for free and open access by the USF Graduate Theses and Dissertations at Digital Commons @ University of South Florida. It has been accepted for inclusion in USF Tampa Graduate Theses and Dissertations by an authorized administrator of Digital Commons @ University of South Florida. For more information, please contact digitalcommons@usf.edu. 
Capturing Resilience in Context:

Development and Validation of a Situational Judgment Test of Resilience

by

\author{
Yuejia Teng \\ A thesis submitted in partial fulfillment \\ of the requirements for the degree of \\ Master of Arts \\ Department of Psychology \\ College of the Arts and Sciences \\ University of South Florida
}

Co-Major Professor: Michael T. Brannick, Ph.D. Co-Major Professor: Walter C. Borman, Ph.D Vicky Phares, Ph.D.

Date of Approval:

August 25, 2017

Keywords: coping, measurement, interactionism, adversity, hardiness, grit Copyright (C) 2017, Yuejia Teng 


\section{Dedication}

I would like to dedicate this thesis to my parents, Guangxin Zhang and Jianping Teng, for their never-ending support and unconditional love throughout my academic and personal life, and my best friend, Xinyue Liu, for her kind heart and being part of my life. I would also like to dedicate this thesis to every brilliant and brave soul struggling and relentlessly overcoming adversity. 


\section{Acknowledgments}

I am eternally indebted to my mentors, Drs. Michael T. Brannick and Walter C. Borman, for their generous support, knowledge, and time throughout my graduate school career. This thesis would not have been completed without their support, insights, wisdom, and academic acumen. I am also genuinely grateful to Dr. Vicky Phares, who served on my committee and provided me with helpful suggestions.

I would like to thank my undergraduate research assistants, Dylan Reeves, Galo Rodriguez, Andrew White, for their time and help with item generation and revision, and item coding. I am also thankful for the help and efforts of Tyler Anderson, Dr. Idan Ariel, Sarah Frick, Claire Gorey, David Howard, Seulki Jang, Elizabeth Kiebel, and Amanda Palmer, who kindly served as expert judges for item evaluation. My sincere gratitude also goes to Dr. Idan Ariel for his friendship as well as insightful comments, and Jacob Levine for his editorial and presentational suggestions. This project would have never come to fruition without the time, efforts, support and friendship they generously provided. 


\section{Table of Contents}

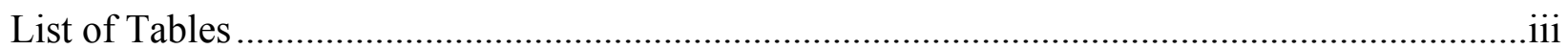

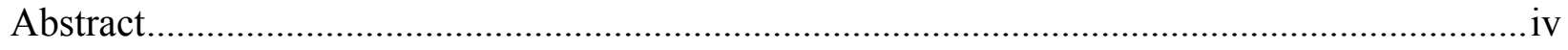

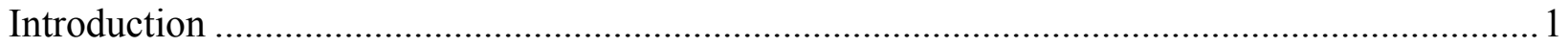

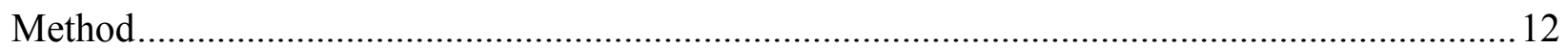

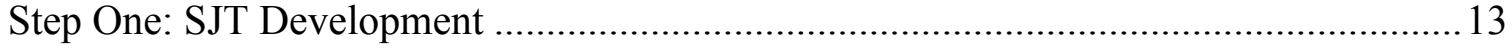

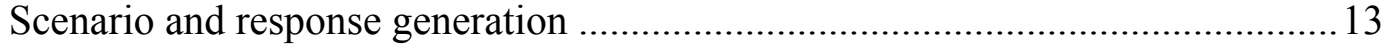

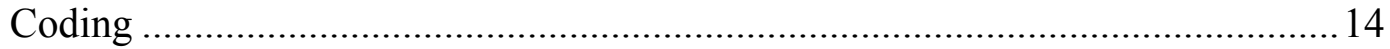

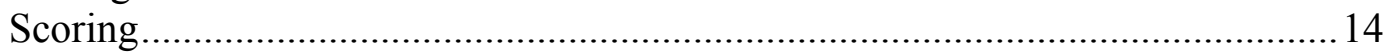

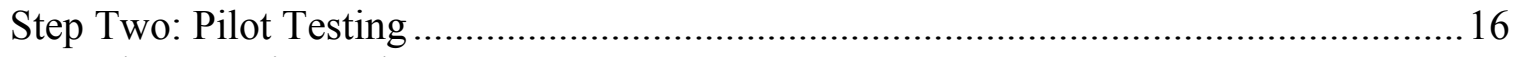

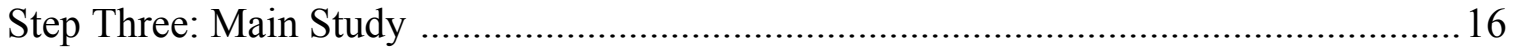

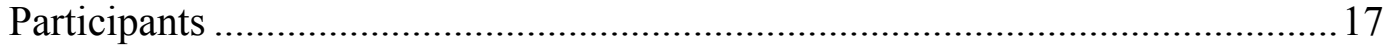

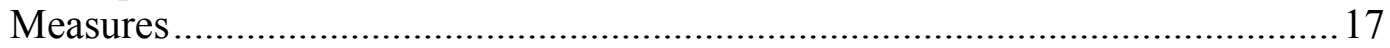

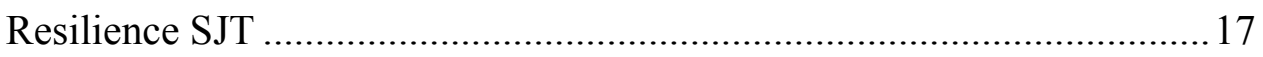

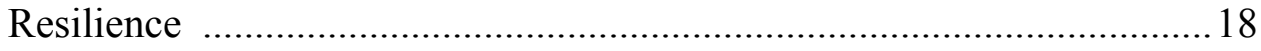

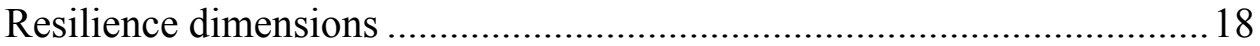

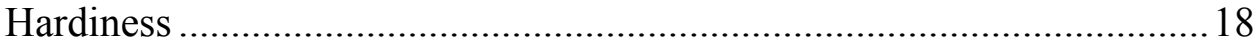

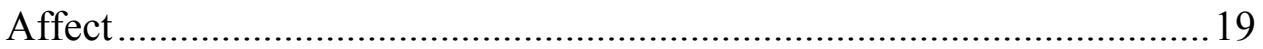

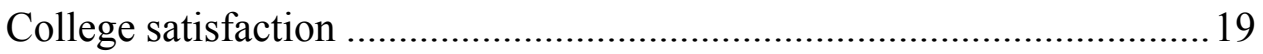

Global adjustment..................................................................... 19

Academic performance ................................................................. 19

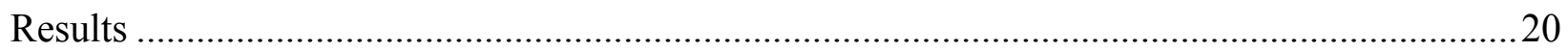

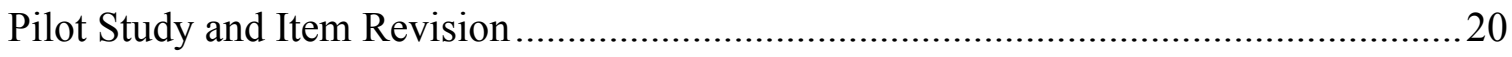

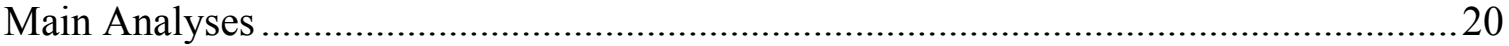

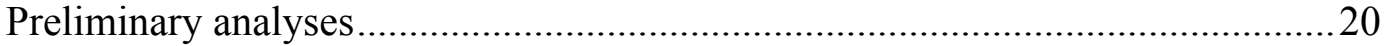

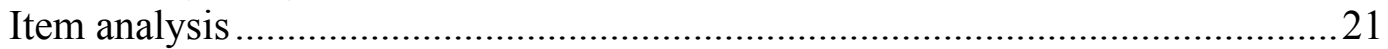

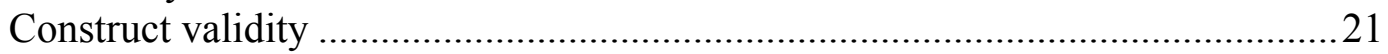

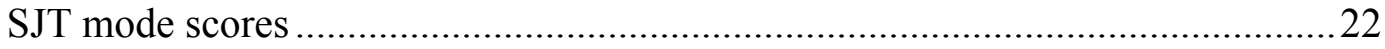

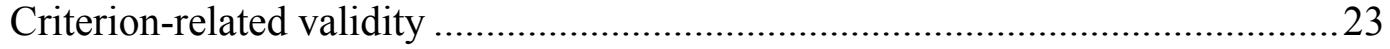

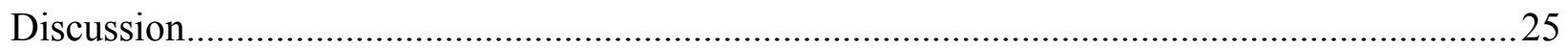

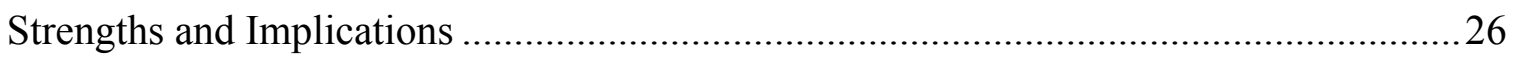

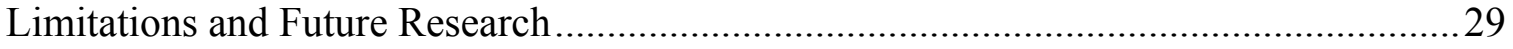

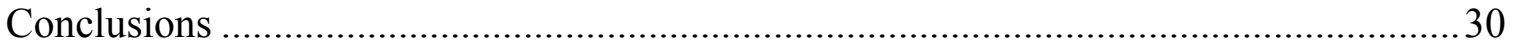

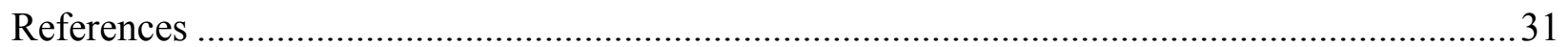


Appendix A: Finalized Resilience SJT Items .......................................................................5

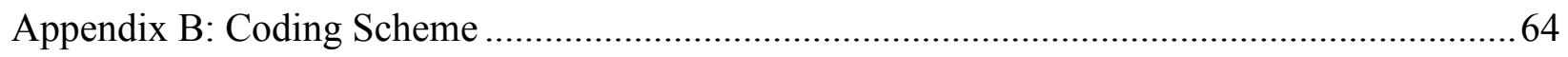

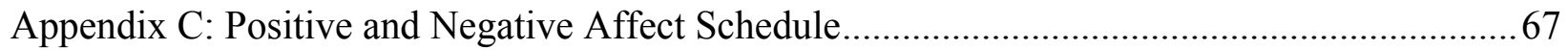

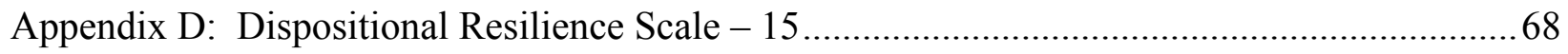

Appendix E: Connor-Davidson Resilience Scale 25 ....................................................................69

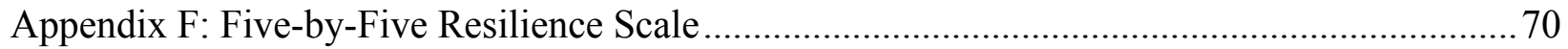

Appendix G: Depression Anxiety Stress Scales - 21 ...........................................................

Appendix H: Perceived Quality of Academic Life …….................................................................72

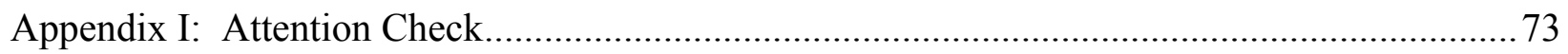

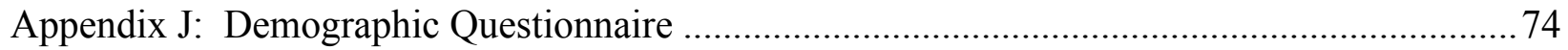

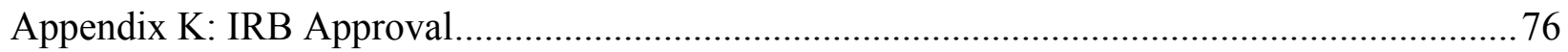




\section{List of Tables}

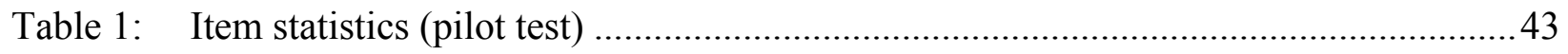

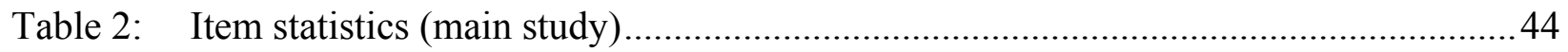

Table 3: Descriptive statistics and bivariate correlations for variables ................................45

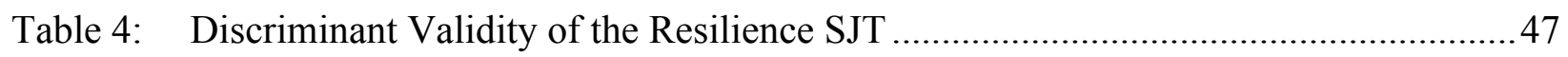

Table 5: Incremental validity of the Resilience SJT in predicting college satisfaction............48

Table 6: Incremental validity of the Resilience SJT in predicting depression .......................49

Table 7: Incremental validity of the Resilience SJT in predicting anxiety...........................50

Table 8: Incremental validity of the Resilience SJT in predicting stress .............................51

Table 9: Incremental validity of the Resilience SJT in predicting cumulative GPA...............52

Table 10: Construct validity correlations of the SJT Resilience mode scores ........................53 


\begin{abstract}
The current study developed a 40-item situational judgment test (SJT) to measure resilience in context. Undergraduate samples were used in the study and situational stems of the SJT consisted of both daily stressors and major life crises; each response alternative was designed to reflect one of five resilience-related factors. A crowd-sourcing method was utilized to create scoring keys for the SJT. The Resilience SJT demonstrated good psychometric properties, and showed evidence of construct and criterion-related validity. The SJT scores moderately correlated with scores from two resilience Likert scales, a hardiness scale as well as a negative affect scale. Compared to the two Likert-type resilience scales, the SJT demonstrated less overlap with hardiness, positive affect, and negative affect. Moreover, the SJT showed incremental validity in predicting global adjustment, but not academic achievement or college satisfaction, above and beyond the two other resilience measures. Lastly, the study examined different modes of resilient behavior and captured individuals' mode choice tendencies for resilient responses to adverse situations. The Resilience SJT appears to be a viable alternative to capture resilience. Implications and limitations were discussed.
\end{abstract}




\section{Introduction}

“Our greatest glory consists not in never falling, but in rising every time we fall." (Ralph Waldo Emerson).

Emerson's wisdom perfectly encapsulates resilient individuals' capacity for bouncing back from failure and adversity. An important psychological construct, resilience has demonstrated positive effects on recovery from traumatic events, overall life satisfaction, psychological distress, physical and mental health, impaired functioning, recovery from posttraumatic stress disorder, fewer depressive symptoms, and psychological strain at work (Assareh, Sharpley, McFarlane, \& Sachdev, 2015; Burns \& Anstey, 2010; Coates, Phares, \& Dedrick, 2013; Crane \& Searle, 2016; Fredrickson, Tugade, Waugh, \& Larkin, 2003; Grossman, 2014; Hu, Zhang, \& Wang, 2015; Seery, Holman, \& Silver, 2010). Psychophysiological research has shown that resilience predicts greater cardiovascular recovery from exposure to stressors and induced negative emotions, demonstrating the physiological roots of resilience (Tugade \& Fredrickson, 2004; Tugade, Fredrickson, \& Barrett, 2004).

Although resilience has received increasing research attention, psychological researchers have yet to reach consensus on how resilience is defined, operationalized, or measured (Britt, Shen, Sinclair, Grossman, \& Klieger, 2016; Davydov, Stewart, Ritchie, \& Chaudieu, 2010; Gucciardi, Jackson, Coulter, \& Mallett, 2011; Windle, 2011). Meredith and colleagues (2011) conducted a comprehensive literature review and found 104 different definitions of resilience that vary in three ways: 1) the ability or process, 2) adaptation and "bouncing back" to the baseline, and 3) growth after recovering from adversity (p.20). Pangallo (2014) conducted an 
additional review and provided the following categories: 1) personality trait, 2) psychological state, 3) process, 4) positive outcome and recovery from adverse events. In a similar vein, Shaikh and Kauppi (2010) synthesized six fine-grained aspects of resilience from existing research: 1) personality traits, 2) positive outcomes/forms of adaptation despite high-risk, 3) factors associated with positive adaptation, 4) processes, 5) sustained competent functioning/stress resistance, and 6) recovery from trauma or adversity. As a result of ambiguous definitions, existing measures do not distinguish resilience as a process, an outcome, or an ability (Pangallo, Zibarras, Lewis, \& Flaxman, 2015; Windle, Bennett, \& Noyes, 2011). For instance, among commonly used resilience measures, the Connor-Davidson Resilience Scale (CD-RISC; Connor \& Davidson, 2003) measures resilience as a personality trait, whereas the Psychological Capital Questionnaire (PCQ; Luthans, Youssef, \& Avolio, 2007) defines resilience as a psychological state. The Resilience Scale for Adults (RSA; Friborg, Hjemdal, Rosenvinge, \& Martinussen, 2003) conceptualizes resilience as a psychological process, whereas the Brief Resilience Scale (BRS; Smith et al., 2008) considers resilience as an outcome (Pangallo, 2014).

Perhaps the most well-known conceptualization of resilience is "the ability to bounce back from adversity" (Grossman, 2014; Luthans, 2002; Pangallo, 2014; Windle, 2011). However, as a key component in resilience, the meaning of "adversity" is ambiguously defined. To date, little agreement exists on what constitutes "adversity" (Pangallo, 2014; Pangallo et al., 2015; Windle, 2011). The majority of psychological scientists would agree that, in resilience research, adversity is one type of acute stressor and refers to "relatively major adverse events," including but not limited to poverty, natural disasters, terrorist attacks, physical and psychological abuse, the death of loved ones, diagnosis of serious medical conditions, and psychological trauma (Assareh et al., 2015; Pangallo, 2014; Pangallo et al., 2015; Seery et al., 
2010; Vanderbilt-Adriance \& Shaw, 2008; Windle, 2011). For example, resilience was associated with better functioning and greater recovery from child bereavement (Infurna \& Luthar, 2017), spousal loss (Bonanno et al., 2002; Infurna \& Luthar, 2016), hurricane Katrina (Lee, Shen, \& Tran, 2009) and the 9/11 terrorist attack (Bonanno, Galea, Bucciarelli, \& Vlahov, 2006; Bonanno, Rennicke, \& Dekel, 2005; Fredrickson et al., 2003).

Some researchers further argue that adversity also consists of cumulative and chronic life stressors (Seery et al., 2010; Vanderbilt-Adriance \& Shaw, 2008; Windle, 2011). Particularly, adverse events often do not happen on a single occasion, but rather co-occur with other adverse events continuously over the lifespan. Examining only major life challenges would neglect the carry-over effects on psychological functioning from one instance of adversity to the next, preventing researchers from exploring how prior life experiences shape individuals' responses to adversity. Additionally, some argue that daily hassles be considered as adversity in addition to major life challenges (Bonanno, 2004; Bonanno, Westphal, \& Mancini, 2011; Green, Wallace, \& Hargrove, 2016; Pangallo et al., 2015; Sameroff \& Rosenblum, 2007). Green and colleagues (2016) asserted that what constitutes adversity is not based only on objective standards, but also on an individual's subjective perceptions and experiences. Depending on individual characteristics, those who are less resilient would perceive daily stress as adversity and in turn sustain noticeable distress, whereas more resilient individuals would cope with daily stress more adaptively. Shoenfelt (2016) noted in her recent commentary, "the challenge of the situation should not have to be so severe that it results in psychological trauma for it to be of interest to resilience researchers" (p.444). Major traumatic events are of extremely low probability; focusing only on adverse events in the objective sense would make it difficult to generalize resilience research to mundane life and work settings (Green et al., 2016). Thus, it may be 
particularly pertinent to examine how resilient individuals cope with daily stress, whereby resilience research could be applied beyond extreme disastrous circumstances (Kuntz, Näswall, \& Malinen, 2016).

Recently, researchers have called for a more process-oriented conceptualization of resilience, and accentuate that resilience is a dynamic process in which individual characteristics interact with the environment (i.e., adversity), the results of which are adaptation to adversity and reduced distress (King \& Rothstein, 2010; Masten, 2001; Meredith et al., 2011; Rothstein, McLarnon, \& King, 2016; Windle, 2011). Through systematic review of previous resilience literature, Windle (2011) concluded that resilience is "the process of effectively negotiating, adapting to, or managing significant sources of stress or trauma. Assets and resources within the individual, their life and environment facilitate this capacity for adaptation and 'bouncing back' in the face of adversity" (p.152). Such a process-oriented perspective may enable researchers to look beyond an individual's traits, and take into account how different types of adversity with varying intensities affect individuals' resilience (Pangallo et al., 2015). As such, the present paper considered resilience as a person $\times$ situation process and concurred that adversity, as key component of resilience, consists of both daily hassles and extreme stressors.

The lack of consensus on defining and operationalizing resilience has impeded progress in developing and refining psychometrically sound measures of resilience (Pangallo et al., 2015; Windle, 2011). Most resilience measures have not been well validated and there are not any universally agreed-upon measure of resilience (Burns \& Anstey, 2010; Campbell-Sills \& Stein, 2007; Coates et al., 2013; DeSimone, Harms, Vanhove, \& Herian, 2016; Pangallo et al., 2015; Windle et al., 2011). Windle and colleagues (2011) assessed psychometric properties of 15 existing resilience scales against a series of criteria and found that only three scales - the CD- 
RISC, the RSA, and the BRS - demonstrated at least moderate psychometric qualities. Recently, Pangallo and colleagues (2015) reviewed articles published through 2013 and evaluated 17 existing resilience measures in terms of internal consistency, stability, replicability, and other psychometric properties. Only 4 of the 17 measures - the CD-RISC, the RSA, the BRS, and the PCQ - fulfilled $80 \%$ of the criteria set for psychometrically sound measures, including theory formulation, internal consistency, stability, replicability, application, and convergent and discriminant validity. Even the most well-known and well-validated measures demonstrate unstable and inconsistent factor structures (Burns \& Anstey, 2010; Campbell-Sills \& Stein, 2007; Coates et al., 2013). Take the CD-RISC as an example; in their original validation study, Connor and Davidson (2003) found that the CD-RISC consisted of five factors. Later, attempting to replicate Connor and Davidson's findings, Campbell-Sills and Stein (2007) administered the measure to two undergraduate samples with similar demographic backgrounds and conducted exploratory factor analyses (EFAs) to compare the factor structures in these two samples. Surprisingly, they found different factor structures within the two samples. Contrary to the five factors identified earlier by Connor and Davidson, only two factors were identified, labeled as hardiness and persistence, which were stable across both samples.

Moreover, current resilience measures tap into seemingly similar yet theoretically distinct constructs. For example, some resilience measures have varying degrees of overlap with psychological hardiness, a related but distinct personality trait (Grossman, 2014). Hardiness is defined as a stable personality trait and consists of three dimensions-commitment, control, and challenge (Eschleman, Bowling, \& Alarcon, 2010; Windle, 2011). Commitment concerns "the extent to which a person is engaged in a variety of life domains," while control refers to "the extent to which a person believes that he or she is able to control events that happen in his or her 
life" (pp.278-279); challenge is "a belief that fulfillment in life results from the growth and wisdom gained from difficult or challenging experiences" (Windle, 2011, p. 163). Pangallo and colleagues (2015) reviewed the factor structures of 17 existing resilience measures and found four scales that conflated resilience with hardiness. The widely adopted CD-RISC was reported to be highly correlated with hardiness, $r=.83$ (See Table 1; Pangallo et al., 2015, p. 5). Conversely, the Dispositional Resilience Scale (DRS; Bartone, 1995, 2007; Bartone, Ursano, Wright, \& Ingraham, 1989) was designed to measure dispositional resilience but taps into hardiness as well. For theoretical development, it is vital that resilience researchers develop better-validated measures that are able to distinguish resilience from hardiness.

Perhaps more concerning, is the fact that most resilience measures are based on selfreported Likert-type scales, limiting the ability of resilience researchers to comprehend the full scope of resilience (Britt et al., 2016; Harms \& Wood, 2016; Pangallo et al., 2015). Self-report measures often ask individuals to indicate to what extent they agree or disagree with resiliencerelated statements, which provides a global assessment of individuals' perceived-self. Selfperception, albeit integral to the understanding of individual differences, is often inaccurate and subject to self-enhancement bias, demand characteristics, and other biases (Dunning, Heath, \& Suls, 2004; Wolfson \& Mulqueen, 2016). Hence, self-reported Likert scales may not accurately reflect individuals' levels of resilience. Further, these scales provide only global representations, neglecting the importance of context in measuring resilience (Pangallo et al., 2015; Wolfson \& Mulqueen, 2016).

Particularly, adversity — a situational component—is entrenched in the conceptualization of resilience, and has varying types and intensities (Meredith et al., 2011; Pangallo et al., 2015; Rothstein et al., 2016; Wolfson \& Mulqueen, 2016). Depending on the nature and intensity of an 
adverse event, individuals may be more or less resilient. They may be resilient when facing harsh criticisms from their superiors, but not when coping with major setbacks in their careers; they may be resilient when suffering heartbreak, but not when grieving for the death of loved ones. Using Likert scale measures may conceal the nuanced interaction of individual characteristics with the situation. Lastly, self-report Likert scales do not capture within-person differences; using only Likert scales is essentially a missed opportunity to investigate behavioral consistency across situations (Pangallo et al., 2015). In particular, resilience manifests in different forms in different situations (Becker \& Ferry, 2016). One type of resilient response may be effective in one context but maladaptive in another. When facing unemployment individuals may demonstrate resilience by adapting to the situation and promptly starting to look for jobs, while they may seek consolation from friends and family when grieving for deaths of loved ones. These within-person variations across different situations may provide valuable information, beyond between-person differences, in predicting future behaviors. Unfortunately, these intraindividual differences are not adequately captured using existing Likert-based measures (Funder, 2009; Pangallo et al., 2015). In this regard, resilience researchers are strongly encouraged to add contextual information to improve extant resilience measures and examine resilience from both within-person and between-person perspectives.

To address the aforementioned issues associated with resilience measures, the present study capitalized on a contextualized assessment method—situational judgment tests (SJTs) — to measure resilience in context. SJTs, also known as "low-fidelity simulations," are designed to capture individuals' judgment on, and responses to, a series of workplace situations (Motowidlo, Dunnette, \& Carter, 1990; Ployhart \& MacKenzie Jr, 2011; Whetzel \& McDaniel, 2009). Respondents are presented a series of vignettes, each with several options to choose from as an 
indication of their responses to the situations; vignettes and corresponding behavioral response options are generally created based on the results of job analysis. Both primary studies and metaanalyses have demonstrated that SJTs possess construct and criterion-related validity (Campion \& Ployhart, 2008; McDaniel, Hartman, Whetzel, \& Grubb, 2007; McDaniel, Morgeson, Finnegan, Campion, \& Braverman, 2001; Ployhart \& MacKenzie Jr, 2011; Whetzel \& McDaniel, 2009). Correspondingly, SJTs have predicted job performance (Christian, Edwards, \& Bradley, 2010; McDaniel et al., 2007; McDaniel et al., 2001; McDaniel \& Nguyen, 2001; Motowidlo et al., 1990), general cognitive abilities (McDaniel et al., 2001), Big Five personality traits (McDaniel \& Nguyen, 2001; Motowidlo, Hooper, \& Jackson, 2006a, 2006b; Whetzel \& McDaniel, 2009), and emotional intelligence (Sharma, Gangopadhyay, Austin, \& Mandal, 2013). It is worth noting that providing situational cues is a unique feature of SJTs. Stemming from the behavioral consistency principle, it has been argued that SJTs assess and predict how individuals will react to these situations in the future, by presenting respondents with scenarios that are likely to occur on the job (Krumm et al., 2015; Whetzel \& McDaniel, 2009). Therefore, using SJTs as a measure of resilience would provide situational scenarios of stressors and thereby may shed fresh light on how resilient individuals perceive and respond to adverse situations (Green et al., 2016). Moreover, adopting the SJT method makes it possible to measure resilience from a person $\times$ situation interactionist framework (Campion \& Ployhart, 2008; Pangallo et al., 2015). Interactionists argue that individuals' behavioral responses result from the dynamic interaction between both their dispositional traits and the situations in which they reside (Mischel, 2009; Mischel \& Shoda, 1995; Tett \& Burnett, 2003). It has been argued that resilience is the dynamic interaction between individuals and their environments (Luthar, Cicchetti, \& Becker, 2000; Pangallo et al., 2015). The interactionist approach may better reflect the nature of 
resilience; using the SJT as a measurement method introduces context as a factor, thereby allowing detection of the interaction between personality and environment (Campion \& Ployhart, 2008; Pangallo et al., 2015). Lastly, previous research suggests that personality measures integrating contextual cues demonstrated better predictive validity than context-independent measures (Shaffer \& Postlethwaite, 2012). Thus, the Resilience SJT was expected to offer advantages when compared to traditional resilience measures.

In short, the present study took advantage of the contextual feature of SJTs to examine resilience from a person $\times$ situation interactionist perspective, exploring whether the SJT would be a viable alternative to measure resilience and how the SJT would fare compared to conventional resilience measures. Adversity, crucial for defining resilience, was conceptualized as experiencing both common daily challenges and acute adverse events. An undergraduate research pool was used as a convenience sample, and the content of the SJT was geared appropriately toward that population. Accordingly, the situational stems of the SJT were designed to include daily struggles and major life crises commonly faced by college students. To examine both within-person variations of resilience and between-person differences, each response alternative for SJT items was designed to be indicative of one of the five resilience modes (i.e., Adaptability, Emotion Regulation, Optimism, Self-efficacy, and Social Support) within the five-factor framework of resilience identified by DiSimone and colleagues (2016). A forced-choice format was adopted, which required respondents to choose one type of resiliencerelated response over others in response to adverse situations. Such design made it possible to delineate individuals' modes of resilience in response to different situations, and probe for factors contributing to resilience. It is worth mentioning that the five modes of resilience included in the present study are by no means exhaustive. Due to the lengthy nature of SJTs and 
the bandwidth-fidelity tradeoff (Judge, Rodell, Klinger, Simon, \& Crawford, 2013), including more factors in the measure necessitates a larger number of items to ensure fidelity, and may subsequently cause participants to experience testing fatigue. DiSimone and colleagues' (2016) five-factor structure of resilience provides a relatively inclusive list of adaptive personality factors that may contribute to resilience. As the primary aim of the present study was to examine whether the SJT would be a viable alternative to measure resilience, DiSimone and colleagues' factor structure provides a reasonable framework to achieve this end.

The current study compared the Resilience SJT with two conventional resilience measures - the CD-RISC and $5 \times 5 \mathrm{RS}$. The CD-RISC is one of the most widely used and accepted resilience measures with adequate psychometric properties (Windle et al., 2011), and was thus used as a "yardstick" to evaluate the SJT in the study. The $5 \times 5$ RS is one of the recently developed multi-dimensional resilience measures demonstrating good reliability as well as construct and criterion-related validity; thus, it was adopted to compare with the SJT in the study. The SJT was expected to demonstrate superiority in terms of discriminant validity and criterion-related validity.

To examine construct validity of the Resilience SJT, scores were correlated with resilience scores obtained from the two Likert-type measures. The SJT scores were expected to show moderate correlations with the resilience scores obtained from the two conventional resilience measures. Existing resilience measures highly conflate resilience with hardiness; in fact, the correlation between hardiness and resilience measured by the CD-RISC is as high as .83 (Pangallo et al., 2015). Thus, hardiness was measured to examine discriminant validity of the SJT. Compared to the CD-RISC and $5 \times 5 \mathrm{RS}$, the SJT was expected to successfully distinguish resilience from hardiness. Trait affect has also been found to significantly correlate with 
resilience (Grossman, 2014; Hu et al., 2015) and, thus, was also measured in the study. The SJT was expected to correlate with both trait affect and hardiness, but the magnitude of the correlation was expected to be small enough that the SJT resilience measure could be clearly distinguished from the others. Additionally, the SJT was hypothesized to demonstrate less overlap with hardiness and trait affect, in terms of variance accounted for, compared to the two Likert-type resilience measures.

College satisfaction, global adjustment, and academic performance were measured to evaluate criterion-related validity and incremental validity beyond the two traditional resilience measures. Previous research suggests that trait resilience significantly correlates with performance, mental health outcomes and adjustment, satisfaction, and well-being (Grossman, 2014; Hu et al., 2015; Lamp, 2013; Sarkar \& Fletcher, 2017). As such, SJT scores were expected to show positive zero-order correlations with participants' college satisfaction, global adjustment, and academic performance. Further, SJT scores were predicted to demonstrate significant incremental validity beyond the two resilience Likert scales in predicting these criterion variables.

Lastly, the present study explored the validity of five modes of resilience (i.e., Adaptability, Emotion Regulation, Optimism, Self-efficacy, and Social Support) by correlating the five SJT mode scores with the $5 \times 5$ RS subscale scores. Specifically, a multitrait-multimethod (MTMM) matrix was computed and examined in light of Campbell and Fiske's (1959) criteria for validity. The correlations between the five traits using different methods (SJT vs. Likert selfreport) were expected to be higher than entries in the same row and column of the heterotrait matrix, demonstrating convergent validity. Conversely, the correlations between different traits using the same methods were expected to be lower, demonstrating discriminant validity. 


\section{Method}

The current study involved three steps, the first of which was the development of resilience SJT items. Prior research suggests that SJTs with response instructions indicating behavioral tendencies correlate highly with the Big Five personality traits (McDaniel et al., 2007; Whetzel \& McDaniel, 2009). Therefore, behavioral tendency instructions "Most vs. Least Likely" were adopted in the SJT to measure resilience. Also, the written format was adopted due to its low cost. Forty Resilience SJT items were generated and a crowd-sourcing method was used to create scoring keys. Next, SJT items were pilot-tested, using undergraduate student samples, in order to assess item quality and guide item revisions. Items with questionable psychometric properties were revised before being included in the main study. The final step was to examine the validity of the Resilience SJT using construct and criterion-oriented data collection designs with undergraduate student samples. To examine convergent and discriminant validity, SJT scores were compared with those from two commonly used Likert-based resilience measures (i.e., the $5 \times 5 \mathrm{RS}$ and the CD-RISC), as well as trait affect and hardiness. To examine criterion-related validity, SJT scores were correlated with participants' satisfaction with their college experience, global adjustment, and academic performance.

Three sets of undergraduate student samples were recruited to create scoring keys, for pilot testing, and to conduct the main study, respectively; the same sampling procedures and inclusion criteria were used in all three samples. Specifically, undergraduate students were recruited from the Department of Psychology at the University of South Florida using SONA systems, and received research credit as compensation. Eligibility criteria were: 1) age of at least 
18 years old and 2) proficiency in English. Those who had participated in prior Resilience SJT research were prohibited from taking part in the study. Participants were instructed to complete the questionnaire online through Qualtrics ${ }^{\circledR}$; careless respondents, speed respondents, and individuals who completed less than $30 \%$ of the survey were excluded from data analyses.

\section{Step One: SJT Development}

Scenario and response generation. First, five subject matter experts (SMEs) were recruited to create critical incidents that led to the scenarios used in the SJT. All SMEs - two Industrial-Organizational (I/O) psychologists and three senior psychology students —had adequate training in the resilience literature. SMEs were asked to generate scenarios and at least five possible behavioral responses to each scenario. The resulting scenarios represent common adverse events experienced in college, as well as major adverse events such as the death of a loved one. As a result, situations included in the Resilience SJT covered a wide range of events from daily stressors related to college students, to major adversity, thereby capturing both conceptualizations of adversity. Additionally, SMEs were asked to generate behavioral response options to represent as closely as possible one of the five modes-Adaptability, Emotion Regulation, Optimism, Self-efficacy, and Social Support. Then, the scenarios and responses were reviewed and revised by two I/O psychologists to ensure the clarity, face validity, and equivalent social desirability of item response options. An example item is listed below (modes are indicated by labels in parentheses after each response).

You are taking an upper level physics class to fulfill a college major requirement. It is one of the hardest courses you have taken and is regarded as a good indicator of future career success. Halfway through the semester, you have completed two course 
projects and you got Cs for both. What would you most likely do? What would you least likely do?

A. Tell yourself that you will do well in the end because you are smart and hardworking (Self-efficacy)

B. Go over the feedback your professor provided on your projects and study accordingly (Adaptability)

C. Decide to switch to a less demanding field since you do not perform well in this one (Emotion Regulation)

D. Tell yourself that this is just a minor setback and things will turn out well in the end (Optimism)

E. Talk to other students in your class for support (Social Support)

Coding. To examine the modes of resilient responding, each response alternative was sorted into one of the five categories - Adaptability, Emotion Regulation, Optimism, Selfefficacy, and Social Support. First, SMEs developed a coding scheme. Four SMEs, two I/O psychologists and two senior psychology students with adequate training in the resilience literature participated in this process. Each response alternative was coded independently; only when at least 3 out of 4 coders were in agreement was the coding adopted for each response alternative. When no agreement was reached, the response was revised to fit into one of the five modes. Redundant responses were discarded if too many of them were representing the same mode to ensure that each mode had approximately the same number of keyed responses throughout the SJT. The finalized coding scheme is presented in Appendix B.

Scoring. The Resilience SJT had two sets of scores, the first of which was a fairly conventional score estimating individuals' overall resilience. Scoring keys for SJT response 
options were generated using a crowd-sourcing method. One hundred and sixty-eight undergraduate students were recruited following the aforementioned sampling procedure to complete 40 SJT pilot items online through Qualtrics ${ }^{\circledR}$. To screen out careless and speed respondents, three attention check items were included and placed randomly in the questionnaire. Attention check items were "I do not understand a word of English," "If you are paying attention to the survey right now, click Very Accurate," and "The sun rotates around the earth." Participants who failed more than $33 \%$ of the attention checks $(N=55)$, or who spent less than 15 minutes on the survey $(N=8)$ were excluded from data analyses, as were those who did not finish $30 \%$ of the survey $(N=5)$. Responses of the remaining 100 participants $\left(M_{\text {age }}=20.31\right.$, $S D_{\text {age }}=4.06,53 \%$ White, $84 \%$ Female) were used to create scoring keys. Proportions of people endorsing "Most Likely" response options were used to calculate the score for "Most Likely" options, and proportions of people endorsing "Least Likely" response options were used to score the "Least Likely" options. The correlation between the proportions of endorsing "Most Likely" options and the proportions of endorsing "Least Likely" options was -.53, $p<.001$. For each SJT item, a respondent's "Most Likely" response was scored by assigning the proportion of endorsing "Most Likely" on the selected option and "Least Likely" response was scored by assigning the proportion of endorsing "Least Likely" on the chosen option. Each SJT item score was computed by taking the sum of the value of the selected "Most Likely" response option and the value of the selected "Least Likely" response option. If either or both of the "Most Likely" and "Least Likely" items were not completed, the responder's score on the item was counted as a missing value. The overall score on the SJT was the mean of all item scores, resulting from dividing the sum of the item scores by the number of items that did not contain missing values. 
The second set reflected five scores that indicated preferred modes of respondingAdaptability, Emotion Regulation, Optimism, Self-efficacy, and Social Support—corresponding with the $5 \times 5$ RS subscales (DeSimone et al., 2016). To calculate the five mode scores, each mode was the number of "Most Likely" responses less the number of "Least Likely" responses for each mode.

\section{Step Two: Pilot Testing}

In order to assess item quality and the need for item revisions, 72 undergraduate students were recruited to complete the 40 SJT pilot items online. The same three attention-check items used in the previous step were included to sift through careless, speed responders. Participants ( $N$ $=12$ ) who failed more than $33 \%$ of the attention checks, spent less than 10 minutes on the survey, or did not finish at least $30 \%$ of the survey were excluded. The remaining 62 participants $\left(M_{\text {age }}=21.07, S D_{\text {age }}=4.14,63.9 \%\right.$ White, $73.8 \%$ Female $)$ were included in the analyses. Responses to the SJT items were aggregated and analyzed to assess psychometric properties. Items with poor item quality (e.g., low item-to-total correlations) were revised before being included in the main study.

\section{Step Three: Main Study}

In order to examine convergent validity, Resilience SJT scores were correlated with resilience scores obtained from both the 25 -item CD-RISC and the $5 \times 5$ RS. To examine discriminant validity of the Resilience SJT, trait affect, measured by the Positive and Negative Affect Schedule scale (PANAS; Watson, Clark, \& Tellegen, 1988), and psychological hardiness, measured by the Dispositional Resilience Scale—15 (DRS-15; Bartone, 2007), were correlated with Resilience SJT scores, with the hypothesis that these correlations were expected to be lower than the convergent validity correlations. College satisfaction, global adjustment, and academic 
performance were used as criterion variables to assess criterion-related validities of the SJT, and incremental validity beyond the two traditional self-report resilience measures. The construct validity of the SJT mode scores was explored by assessing their correlations with the $5 \times 5 \mathrm{RS}$ subscale mean scores, in adherence with the Campbell and Fiske (1959) MTMM criteria.

Participants. Two hundred and sixty-one undergraduates were recruited following the aforementioned sampling procedure to participate in an online study through Qualtrics ${ }^{\circledR}$. To screen out careless and speed responders, three attention-check items (e.g., "If you are paying attention right now, select slightly disagree") were included and placed randomly in the questionnaire. Participants $(N=46)$ failed more than $33 \%$ of the attention checks and were thus excluded from subsequent analyses. Participants $(N=4)$ who spent less than 10 minutes on the survey, or did not complete more than $30 \%$ of the survey were also excluded. The remaining 211 participants were used in subsequent analyses. Participants had a mean age of 21.07 years $(S D=$ 4.38), and worked 16.07 hours per week on average $(S D=14.07) .50 .7 \%$ of the participants were White, and $76.1 \%$ were female. See Appendix B for the full survey presented to these participants.

Measures. Seven measures, in addition to the Resilience SJT, were included in the main study to examine construct and criterion-related validity of the Resilience SJT: the two Likertbased resilience scales and measures of trait affect, hardiness, college satisfaction, global adjustment, and academic performance. See Table 3 for measure reliability coefficients.

Resilience SJT. After pilot-testing and revising 8 of the 40 pilot SJT items, 40 SJT items were used to measure overall trait resilience and the five modes of resilience (i.e., Adaptability, Emotion Regulation, Optimism, Self-efficacy, Social Support). Each item comprised one situational scenario and several response alternatives; participants were asked to choose their 
most and least likely responses among the alternatives for each scenario. Overall mean resilience scores and mode scores were used in subsequent analyses (see SJT development section for scoring details). See Appendix A for the finalized 40 SJT items used in the main study.

Resilience. The CD-RISC (Connor \& Davidson, 2003), a 25-item measure, was used to measure trait resilience. Participants were asked to indicate the extent to which the statements would apply to them over the past month on a 5-point scale ranging from 0 (Not true at all) to 4 (True nearly all of the time). Sample items are "I can deal with whatever comes my way" and "Even when things look hopeless, I don't give up." Sum scores were used in subsequent analysis.

Resilience dimensions. The $5 \times 5$ RS (DeSimone et al., 2016) is a 25 -item scale designed to assess the five-dimensional structure of resilience (Adaptability, Emotion Regulation, Optimism, Self-efficacy, and Social Support), with 5 items for each dimension. Participants were instructed to indicate the extent to which each statement would accurately describe them on a 5point Likert scale $(1=$ Very inaccurate, $5=$ Very accurate $)$. Sample items are "can switch gears easily" (Adaptability), "experience my emotions intensely" (Emotion Regulation), "Look at the bright side of life" (Optimism), "am good at analyzing problems" (Self-efficacy), and "make friends easily" (Social Support). Mean scores for the overall scale and for subscales were used in the analyses.

Hardiness. The DRS-15 (Bartone, 2007), a 15-item measure, was used to measure psychological hardiness. Participants were asked to indicate their responses on a 4-point Likert scale $(0=$ not at all true, $3=$ completely true $)$. Sample items are "Most of my life gets spent doing meaningful things" and "By working hard you can almost always achieve your goals." Mean scores of all items were used in the analyses. 
Affect. The PANAS (Watson et al., 1988) was adopted to measure Positive Affect (PA) and Negative Affect (NA). The PANAS consists of PA and NA subscales, 5 items for each subscale. Participants were asked to indicate on a 5-point Likert scale $(1=$ Very slightly or not at all, $5=$ Extremely) how they generally felt with 10 words in the PA subscale (e.g., "excited") and the NA subscale (e.g., "distressed"). Mean scores for each subscale were used in the analyses.

College satisfaction. The Perceived Quality of Academic Life (PQAL; Okun, Kardash, Stock, N., \& Baumann, 1986), a six-item measure, was used to measure college students' levels of satisfaction with their college experience. Participants were instructed to indicate how they felt about their college experiences (e.g., "How do you feel about the progress you are making toward your educational goals?") on a 7-point Likert Scale $(0=$ Terrible, $6=$ delighted $)$. Overall mean scores were used in the analyses.

Global adjustment. The Depression Anxiety Stress Scales - 21 (DASS - 21; Lovibond \& Lovibond, 1995) was used to assess participants' global adjustment. The DASS - 21 is a 21 -item measure that includes three subscales-Depression, Anxiety, and Stress, with 7 items for each subscale. Participants were asked to indicate the extent to which the statements applied to them over the past week on a scale ranging from 0 to $3(0=$ Did not apply to me at all, $1=$ Applied to me to some degree, or some of the time, 2 =Applied to me to a considerable degree, or a good part of time, 3 = Applied to me very much, or most of the time). Sample items are "I couldn't seem to experience any positive feeling at all" (Depression), "I was worried about situations in which I might panic and make a fool of myself" (Anxiety), and "I found it hard to wind down" (Stress). Sum scores for each subscale were used in the data analyses.

Academic performance. Participants reported their cumulative grade-point-average (GPA), on a 0.00 -to-4.00 scale, as a measure of their academic performance. 


\section{Results}

Data analysis was conducted using $\mathrm{R}$ Version 3.2.4. The psych package was used to conduct item analyses on the Resilience SJT pilot and revised items. The lm.beta and stats packages were used to conduct regression analyses. Lastly, the Hmisc package was used to obtain descriptive statistics and correlation coefficients, while the Car and Graphics packages were used to check assumptions of linear regression.

\section{Pilot Study and Item Revision}

Item analysis on the Resilience SJT pilot items was conducted to assess item psychometric properties (see Table 1). Cronbach's $\alpha$ for the overall SJT was .80. First, item variances were examined; no items were revised or eliminated as all items produced adequate variances. Then, corrected item-to-total correlations were examined. Seven items (Items 1, 14, 27-31) produced item-to-total correlations less than .2 and were thus revised. Item 6 was revised to make response alternatives more plausible. In short, eight items were revised in this process and 40 items in total were included for the main validation study. See Appendix A for the finalized SJT items.

\section{Main Analyses}

Preliminary analyses. Assumption checks were conducted on the linearity and normality of the variables. Scatterplots among all variables of interest indicated no severe violation of linearity assumption. Thirteen outliers were identified through residual analysis on the multiple regression of the SJT on hardiness, PA, and NA. After excluding these outliers, the same regression analysis was conducted and did not indicate noticeable differences compared to the 
original analysis. Thus, all outliers were retained and the original analysis was used. Only global adjustment scores (Depression, Anxiety, Stress) had severe violations of the assumption of normality. Scores on Depression, Anxiety, and Stress subscales were log-transformed and entered in the same regression analyses. Only the regression of log-transformed Depression scores suggested different inferences compared to the non-transformed ones. Thus, the results of the regression of log-transformed Depression scores were used.

Item analysis. Item analysis on the revised Resilience SJT was conducted to investigate item quality. Cronbach's $\alpha$ for the overall SJT was .86. Item statistics (means and standard deviations), item-to-total correlations and alpha-if-item-deleted are displayed in Table 2. Only one item had an item-to-total correlation below .20 and alpha-if-item-deleted revealed that excluding any item would not produce noticeable increment on overall reliability. Thus, all 40 items were retained and the SJT score was calculated by taking the mean of all 40 items.

Construct validity. Means, standard deviations, reliability coefficients and bivariate correlations of all variables are shown in Table 3. Convergent validity was investigated by correlating Resilience SJT scores with scores on the CD-RISC (Connor \& Davidson, 2003) and the $5 \times 5$ RS (DeSimone et al., 2016). As shown in Table 3, the Resilience SJT scores were moderately correlated with scores on the CD-RISC (Connor \& Davidson, 2003), $r=0.32, p<$ .001 , and scores on the $5 \times 5$ RS (DeSimone et al., 2016), $r=0.43, p<.001$, providing some support for convergent validity of the SJT. Additionally, the SJT demonstrated expected correlations with relevant personality variables. Specifically, the SJT scores significantly correlated with hardiness, $r=0.42, p<.001$, and significantly negatively correlated with NA, $r$ $=-0.40, p<.001$. The SJT also demonstrated a positive, though not significant correlation with PA, $r=0.13, p=.06$. By and large, the Resilience SJT correlated equally strongly with 
personality correlates (i.e., hardiness and NA), as with the two Likert-based resilience measures. Thus, it is reasonable to conclude that the SJT demonstrated moderate convergent validity and warrants further investigation.

To compare discriminant validity of the Resilience SJT with that of the two Likert-based resilience measures (i.e., the CD-RISC and $5 \times 5 \mathrm{RS}$ ), three separate multiple regression analyses were conducted to compare the extent to which variances in the three resilience measures were accounted for by trait affect (i.e., PA and NA) and hardiness. As such, hardiness, PA, and NA were entered as predictors into three multiple linear regressions to predict the SJT, the CD-RISC, and $5 \times 5$ RS respectively. As shown in Table 4 , the SJT scores were significantly predicted by hardiness $(B=0.01, S E=0.00, p<0.001)$ as well as NA $(B=-0.03, S E=0.01, p<0.001)$, but not PA $(B=-0.01, S E=0.01, p=.15)$. The three predictors accounted for $24 \%$ of the total variance in the SJT. In comparison, scores on the CD-RISC were significantly predicted by hardiness $(B=1.31, S E=0.17, p<0.001)$ as well as PA $(B=5.49, S E=-1.00, p<0.001)$, but not NA $(B=-1.46, S E=-1.05, p=.16)$; the three predictors accounted for $56 \%$ of the total variance in the CD-RISC. In addition, the $5 \times 5 \mathrm{RS}$ scores were significantly predicted by hardiness $(B=0.04, S E=0.01, p<0.001)$, PA $(B=0.18, S E=0.03, p<0.001)$, and NA $(B=$ $0.29, S E=0.03, p<.001)$; the three predictors accounted for $66 \%$ of the total variance in the $5 \times 5$ RS. It is evident that the Resilience SJT had less variance overlap with PA, NA, and hardiness than did the CD-RISC and the $5 \times 5 \mathrm{RS}$, and thus suffered less from construct contamination as compared to the two Likert-based resilience measures.

SJT mode scores. The construct validity of the Resilience SJT mode scores was assessed using the MTMM matrix presented in Table 10. Contrary to what was expected, effects were more prominent within the hetero-trait mono-method matrices than within the mono-trait hetero- 
method matrix. The Adaptability mode $(M=6.41, S D=5.40)$ demonstrated some convergence with the $5 \times 5$ RS adaptability subscale, $r=.21, p<.001$, as did the Emotion Regulation mode ( $M$ $=-9.17, S D=5.54), r=-.17, p<.05$; the Optimism $(M=0.52, S D=3.82)$, Self-efficacy $(M=$ 2.13, $S D=3.26)$, and Social Support $(M=0.13, S D=5.02)$ modes did not show convergence with the respective $5 \times 5$ RS subscales. The SJT mode scores did not show good discriminant validity, as evidenced by hetero-trait mono-method and hetero-trait hetero-method correlations that were stronger than the mono-trait hetero-method correlations. Correlations of the SJT mode scores with the three resilience scores (i.e., the SJT, CD-RISC, and 5×5 RS) and expected nomological net are also presented in Table 10. The SJT scores significantly correlated with all modes except Social Support, the correlation with the Emotion Regulation mode being the strongest, $r=-.71, p<.001$. The CD-RISC, $5 \times 5$ RS, NA, and hardiness scores significantly correlated with Adaptability, Emotion Regulation, and Self-efficacy modes, with correlations ranging from -.34 (Emotion Regulation with hardiness) to .32 (Emotion Regulation with NA). Global adjustment (i.e., Depression, Stress, and Anxiety) significantly correlated with Emotion Regulation, Optimism, and Self-efficacy modes, and depression was significantly related to the Adaptability mode. Compared to the correlations of SJT scores with the expected nomological net, correlations of the mode scores with the same variables were much weaker, suggesting that the mode scores might not provide unique information beyond the overall SJT score.

Criterion-related validity. As shown in Table 3, the SJT was significantly negatively correlated with the global adjustment Depression, Stress, and Anxiety subscales. The SJT was not significantly correlated with either academic performance (i.e., cumulative GPA) or college satisfaction. Moreover, hierarchical regression analyses were conducted to probe the incremental validity of the SJT beyond the CD-RISC and $5 \times 5 \mathrm{RS}$ in predicting the three criterion variables. 
For each outcome variable, both the mean scores on the CD-RISC and $5 \times 5 \mathrm{RS}$ were entered as predictors in the regression model in the first step. The Resilience SJT scores were added to the restricted model in the second step. As shown in Tables 5-9, the SJT explained significant additional variance beyond the CD-RISC and $5 \times 5 \mathrm{RS}$, in the global adjustment Depression, Anxiety, and Stress subscales. The SJT did not account for incremental variance in college satisfaction or academic performance, beyond the two Likert-type resilience scales. 


\section{Discussion}

The primary aim of the current study was the development of a 40-item Resilience SJT to measure resilience in context. Adversity, essential to the definition of resilience, was conceptualized as daily challenges and major traumatic events, and the SJT scenarios were generated accordingly. Additionally, the study probed both within-person variation and betweenperson differences. Response alternatives for the SJT were created to indicate one of five modes of resilience (i.e., Adaptability, Emotion Regulation, Optimism, Self-efficacy, and Social Support). The Resilience SJT demonstrated good psychometric properties, including construct validity, criterion-related validity, and incremental validity above and beyond two conventional Likert-type resilience measures. Specifically, the SJT exhibited moderate convergent validity with the CD-RISC and $5 \times 5 \mathrm{RS}$, and moderate correlations with hardiness and NA. The SJT also significantly predicted global adjustment (i.e., Depression, Anxiety, and Stress) above and beyond the two conventional resilience measures.

A thorough review of the literature indicates that, to the best of our knowledge, the present study is the first to examine whether SJTs could be used as an effective method to capture resilience. There are several psychometric properties of the Resilience SJT that merit attention. First, the Resilience SJT demonstrated high item quality and internal consistency, as evidenced by internal consistency and item-to-total correlations. No items were discarded or revised after the main validation study and Cronbach's alpha was as high as .86, considerably above the .70 cutoff (Nunnally, 1978; Nunnally \& Bernstein, 1994). Second, the SJT

demonstrated expected convergent validity with the two Likert-type resilience measures and 
related personality correlates. It is worth noting that, in contrast to the high correlation between the CD-RISC and $5 \times 5 \mathrm{RS}(r=.65)$, the SJT was only moderately correlated with the CD-RISC $(r=.32)$ and $5 \times 5 \mathrm{RS}(r=.43)$, indicating weaker convergent validity. However, the Resilience SJT also demonstrated weaker correlations with PA, NA, and hardiness than the CD-RISC and $5 \times 5 \mathrm{RS}$, suggesting that the SJT might have stronger discriminant validity and less construct contamination. Indeed, these three personality correlates (PA, NA, and hardiness) accounted for only $24 \%$ of the total variance in the Resilience SJT; in contrast, they explained $56 \%$ and $66 \%$ of the variance in the CD-RISC and $5 \times 5$ RS respectively.

Third, the Resilience SJT demonstrated less overlap with hardiness, as evidenced by a moderate correlation with hardiness $(r=.42)$. In comparison, hardiness was highly correlated with the CD-RISC $(r=.70)$ and $5 \times 5 \mathrm{RS}(r=.72)$. Thus, it is reasonable to conclude that the SJT may be more effective at differentiating resilience from hardiness. Finally, the SJT showed criterion-related validity and incremental validity in predicting global adjustment (i.e., Depression, Anxiety, and Stress) beyond the CD-RISC and $5 \times 5$ RS. However, the SJT did not significantly predict college satisfaction, potentially due to ceiling effects. Nor did it predict academic achievement, which may have been due to participants inaccurately reporting their cumulative GPAs (Guenther \& Alicke, 2010; Kruger \& Dunning, 1999). On the whole, the Resilience SJT demonstrated expected psychometric properties and validity. Thus, these findings provide evidence that the SJT may be a viable alternative to measuring resilience with traditional Likert-type scales.

\section{Strengths and Implications}

Several features of the current study are worth mentioning. First, the present study took advantage of the situational judgment feature of SJTs, incorporating situational components into 
a resilience measure. Recent research strongly argues that resilience consists of both individual characteristics and situations (Harms \& Wood, 2016; Pangallo et al., 2015). Yet, existing Likerttype resilience measures neglect situational components, and only rely on respondents' global self-perception to measure resilience. The present study capitalized on the contextualized nature of SJTs and asked respondents to indicate their behavioral tendency in response to situational demands. The contextualized feature appears promising. Compared to the two Likert-type measures (i.e., the CD-RISC and $5 \times 5 \mathrm{RS}$ ), the SJT better differentiated resilience from hardiness and trait affect, and was more predictive of global adjustment. These findings support the importance of including contextual cues when measuring resilience.

Previous research findings indicate that contextualized personality measures serve as better predictors of workplace behaviors compared to non-contextualized measures (Shaffer \& Postlethwaite, 2012). It has been argued that the increase in criterion-related validity is mainly due to contextualized measures imposing a "frame of reference" on respondents, and thus reduce within-person inconsistencies (Lievens, De Corte, \& Schollaert, 2008). It is possible that the Resilience SJT presented the same frame of reference, such that respondents had less ambiguity when answering the SJT compared to generic Likert-type measures, and thus produced better construct and criterion-related validity. Moreover, it has been found that to show increased validity the context (frame of reference) of the measure should be conceptually consistent with the criterion space. The scenarios used in the SJT were closely related to situations faced by college students and the criterion measures were chosen to reflect college-related outcomes. This congruence between the SJT scenarios and the criteria might also contribute to the superior validity of the SJT. Future research needs to further explore the mechanism through which resilience SJTs perform better than conventional Likert-type resilience measures. 
Furthermore, this study conceptualized adversity as consisting of both daily challenges and major traumatic events, as opposed to only considering significant life crises. Resilience SJT scenarios were created to represent hassles frequently encountered by college students as well as major life crises with low probability of occurring. Such conceptualization may facilitate generalizing the results of resilience research to daily life beyond life crises (Green et al., 2016). Particularly, SJTs are considered low-fidelity simulations and are largely based on the behavioral consistency principle; that is, responses indicated on the SJT are assumed to be consistent with actual behaviors in naturalistic settings (Weekley, Hawkes, Guenole, \& Ployhart, 2015; Whetzel \& McDaniel, 2009). The course of action indicated on the Resilience SJT may be indicative of respondents' behavior when facing the same situation in real life; however, researchers need to examine whether responses on the Resilience SJT are consistent with individuals' actual behavior in response to daily hassles in real life.

Finally, the current study incorporated five commonly agreed-upon dimensions of resilience and explored the potential of capturing individuals' different modes of resilience. Particularly, each response option for SJT items were created to represent one of the five modes (Adaptability, Emotion Regulation, Optimism, Self-efficacy, Social Support) and a forced-choice format was used in which respondents were asked to choose one mode over the others as their Most vs. Least Likely course of action. Such design made it possible to capture individuals' predisposition to one mode of resilience in the face of adversity even when that mode may not be the most adaptive in a given situation. However, support for the construct validity of the SJT mode scores was discouraging. The correlations of mode scores with expected nomological net were much weaker than the correlations of the SJT scores. Future research needs to explore other methods to capture modes of resilience. 


\section{Limitations and Future Research}

The present study is not without limitations. First, the current study used undergraduate student samples, and as a result the content of the SJT and selected criterion variables were geared toward college students. The results of the study may not to be generalizable to working populations, or of interest to organizations. However, it is worth noting that the contextual focus on college life provided the present study with a wide variety of adverse scenarios not seen in other contexts (e.g., workplace); SJT scenarios based on college life may have covered a wider range of adversity than would be expected in other situations. Additionally, criterion variables assessed in this study closely resemble job-related outcomes that are relevant to organizations. Academic achievement is analogous to job performance, global adjustment to work stress/strain, and college satisfaction to job satisfaction. Findings in the present study may give organizations a general idea as how well the Resilience SJT would predict outcomes. The present study is the first step to develop job-related resilience SJTs.

Second, the present study did not consider general mental ability (GMA); responding to SJTs requires verbal fluency and a certain level of cognitive ability (Whetzel \& McDaniel, 2009). Individuals with higher cognitive ability would be better judge of the presented situations and generate more effective responses. In fact, previous research suggests that SJTs are related to GMA, such that individuals with higher GMA consistently perform better than those with lower GMA. However, the Resilience SJT takes on the "would do" instruction form, which is shown to relate less with cognitive ability than with personality (McDaniel et al., 2007; Whetzel \& McDaniel, 2009). Thus, cognitive ability may not be a factor that has affected participants' responses on the Resilience SJT. Further, the present study showed that participants' cumulative GPA, a factor influenced by cognitive ability (Ployhart \& Holtz, 2008; Sackett, Borneman, \& 
Connelly, 2008), was not correlated with scores on the Resilience SJT. Therefore, it is unclear whether cognitive ability is a relevant factor in the current context, and remains to be explored.

Last, even though the Resilience SJT was shown to be effective at parsing out resilience from hardiness, the present study did not investigate the possibility that the Resilience SJT could distinguish resilience from grit, a similar construct, in additional to hardiness. Grit refers to "perseverance and passion for long-term goals" (Duckworth, Peterson, Matthews, \& Kelly, 2007; Duckworth \& Quinn, 2009) and consists of two dimensions: consistency of interests and perseverance of effort. Current research often conflates resilience with grit and hardiness, partly due to existing resilience measures often tapping into these two constructs (Paterson \& Harms, 2017). The present study suggests that resilience measured by the Resilience SJT overlaps less with hardiness, compared to the traditional Likert-type measures. It is possible that the SJT would demonstrate similar advantages over other resilience measures in distinguishing resilience from seemingly similar constructs such as grit. Future research needs to examine how the Resilience SJT fares in this regard.

\section{Conclusions}

To the best of my knowledge, no resilience SJTs has been developed to capture the intrapersonal and situational nature of resilience (Pangallo et al., 2015). The current study explored a novel approach to measure resilience in context, and supported the potential benefits of using SJTs to capture the complex person $\times$ situation nature of resilience and predict important outcomes better than traditional measures. Future research applying the SJT approach to measuring resilience in workplace environments appears promising, and may help organizational scientists understand and improve employees' resilience in the face of adversity. 


\section{References}

Assareh, A. A., Sharpley, C. F., McFarlane, J. R., \& Sachdev, P. S. (2015). Biological determinants of depression following bereavement. Neuroscience and Biobehavioral Reviews, 49, 171-181.

Bartone, P. T. (1995). A short hardiness scale. Paper presented at the the annual convention of the American Psychological Society, New York, NY.

Bartone, P. T. (2007). Test-retest reliability of the dispositional resilience scale-15: A brief hardiness scale. Psychological Reports, 101(3), 943-944.

Bartone, P. T., Ursano, R. J., Wright, K. M., \& Ingraham, L. H. (1989). The impact of a military air disaster on the health of assistance workers: A prospective study. The Journal of Nervous and Mental Disease, 177, 317-328.

Becker, T. E., \& Ferry, D. L. (2016). Profiles as a way of learning more about resilience. Industrial And Organizational Psychology: Perspectives On Science And Practice, 9(2), 503-508.

Bonanno, G. A. (2004). Loss, trauma, and human resilience: Have we underestimated the human capacity to thrive after extremely aversive events? American Psychologist, 59(1), 20-28.

Bonanno, G. A., Galea, S., Bucciarelli, A., \& Vlahov, D. (2006). Psychological resilience after disaster new york city in the aftermath of the september 11 th terrorist attack. Psychological Science, 17(3), 181-186. 
Bonanno, G. A., Rennicke, C., \& Dekel, S. (2005). Self-enhancement among high-exposure survivors of the september 11 th terrorist attack: Resilience or social maladjustment? $J$ Pers Soc Psychol, 88(6), 984-998.

Bonanno, G. A., Westphal, M., \& Mancini, A. D. (2011). Resilience to loss and potential trauma. Annual Review of Clinical Psychology, 7, 511-535.

Bonanno, G. A., Wortman, C. B., Lehman, D. R., Tweed, R. G., Haring, M., Sonnega, J., . . . Nesse, R. M. (2002). Resilience to loss and chronic grief: A prospective study from preloss to 18-months postloss. J Pers Soc Psychol, 83(5), 1150-1164.

Britt, T. W., Shen, W., Sinclair, R. R., Grossman, M. R., \& Klieger, D. M. (2016). How much do we really know about employee resilience? Industrial And Organizational Psychology: Perspectives On Science And Practice, 9(2), 378-404.

Burns, R. A., \& Anstey, K. J. (2010). The connor-davidson resilience scale (cd-risc): Testing the invariance of a uni-dimensional resilience measure that is independent of positive and negative affect. . Personality and Individual Differences, 48, 527-531.

Campbell, D. T., \& Fiske, D. W. (1959). Convergent and discriminant validation by the multitrait-multimethod matrix. Psychological Bulletin, 56(2), 81-105.

Campbell-Sills, L., \& Stein, M. B. (2007). Psychometric analysis and refinement of the connordavidson resilience scale (cd-risc): Validation of a 10-item measure of resilience. Journal of Traumatic Stress, 20, 1019-1029.

Campion, M. A., \& Ployhart, R. E. (2008). Assessing personality with situational judgment measures: Interactionist pyshcology operationalized. In N. Christiansen \& R. Tett (Eds.), Handbook of personality at work (pp. 439-456). New York, NY: Rutledge. 
Carver, C. S., Scheier, M. E., \& Weintraub, J. K. (1989). Assessing coping strategies: A theoretically based approach. Journal of Personality and Social Psychology, 56, 267-283.

Christian, M. S., Edwards, B. D., \& Bradley, J. C. (2010). Situational judgment tests: Constructs assessed and a meta-analysis of their criterion-related validities. Personnel Psychology, 63(1), 83-117.

Coates, E. E., Phares, V., \& Dedrick, R. F. (2013). Psychometric properties of the connordavidson resilience scale 10 among low-income, african american men. Psychological Assessment, 25(4), 1349-1354.

Connor, K. M., \& Davidson, J. R. T. (2003). Development of a new resilience scale: The connordavidson resilience scale (cd-risc). Depression and Anxiety, 18, 76-82.

Crane, M. F., \& Searle, B. J. (2016). Building resilience through exposure to stressors: The effects of challenges versus hindrances. Journal of Occupational Health Psychology.

Davydov, D. M., Stewart, R., Ritchie, K., \& Chaudieu, I. (2010). Resilience and mental health. Clinical Psychology Review, 30, 479-495.

DeSimone, J. A., Harms, P. D., Vanhove, A. J., \& Herian, M. N. (2016). Development and validation of the five-by-five resilience scale. Assessment, 24(6), 778-797.

Duckworth, A. L., Peterson, C., Matthews, M. D., \& Kelly, D. R. (2007). Grit: Perseverance and passion for long-term goals. Journal of Personality and Social Psychology, 92(6), 10871101.

Duckworth, A. L., \& Quinn, P. D. (2009). Development and validation of the short grit scale (grit-s). Journal of Personality Assessment, 9(2), 166-174.

Dunning, D., Heath, C., \& Suls, J. M. (2004). Flawed self-assessment: Implications for health, education, and the workplace. Psychological Science in the Public Interest, 5(3), 69-106. 
Eschleman, K. J., Bowling, N. A., \& Alarcon, G. M. (2010). A meta-analytic examination of hardiness. International Journal of Stress Management, 17(4), 277-307.

Fredrickson, B. L., Tugade, M. M., Waugh, C. E., \& Larkin, G. R. (2003). What good are positive emotions in crises? A prospective study of resilience and emotions following the terrorist attacks on the united states on september 11th, 2001. Journal of Personality and Social Psychology, 84(2), 365-376.

Friborg, O., Hjemdal, O., Rosenvinge, J. H., \& Martinussen, M. (2003). A new rating scale for adult resilience: What are the central protective resources behind healthy adjustment? . International Journal of Methods in Psychiatric Research, , 12, 65-76.

Funder, D. C. (2009). Persons, behaviors and situations: An agenda for personality psychology in the postwar era. Journal of Research in Personality, 43(2), 120-126.

Green, J. P., Wallace, D. M., \& Hargrove, A. K. (2016). Exploring workplace resilience through a personality strength lens. Industrial And Organizational Psychology: Perspectives On Science And Practice, 9(2), 447-452.

Grossman, M. R. (2014). Clarifying the nature of resilience: A meta-analytic approach. (Unpublished master's thesis), University of South Florida, Tampa, FL.

Gucciardi, D. F., Jackson, B., Coulter, T. J., \& Mallett, C. J. (2011). The connor-davidson resilience scale (cd-risc): Dimensionality and age-related measurement invariance with australian cricketers. Psychology of Sport and Exercise, 12(4), 423-433.

Guenther, C. L., \& Alicke, M. D. (2010). Deconstructing the better-than-average effect. Journal of Personality and Social Psychology, 99(5), 755-770. 
Harms, P. D., \& Wood, D. (2016). Bouncing back to the future: A look at the road ahead for the assessment of resilience. Industrial And Organizational Psychology: Perspectives On Science And Practice, 9(2), 436-442.

Hu, T., Zhang, D., \& Wang, J. (2015). A meta-analysis of the trait resilience and mental health. Personality and Individual Differences, 76, 18-27.

Infurna, F. J., \& Luthar, S. S. (2016). The multidimensional nature of resilience to spousal loss. Journal of Personality and Social Psychology.

Infurna, F. J., \& Luthar, S. S. (2017). Parents' adjustment following the death of their child: Resilience is multidimensional and differs across outcomes examined. Journal of Research in Personality, 68, 38-53.

John, O. P., Robins, R. W., \& Pervin, L. A. (2008). Handbook of personality: Theory and research (3rd ed.). New York, NY: Guilford Press.

Judge, T. A., Rodell, J. B., Klinger, R. 1., Simon, L. S., \& Crawford, E. R. (2013). Hierarchical representations of the five-factor model of personality in predicting job performance: Integrating three organizing frameworks with two theoretical perspectives. Journal of Applied Psychology, 98(6), 875-925.

King, G. A., \& Rothstein, M. G. (2010). Resilience and leadership: The self-management of failure. In M. G. Rothstein \& R. J. Burke (Eds.), Self-management and leadership development (pp. 361-394). Cheltenham, UK: Edward Elgar.

Kruger, J., \& Dunning, D. (1999). Unskilled and unaware of it: How difficulties in recognizing one's own incompetence lead to inflated self-assessments. Journal of Personality and Social Psychology, 77(6), 1121-1134. 
Krumm, S., Lievens, F., Hüffmeier, J., Lipnevich, A. A., Bendels, H., \& Hertel, G. (2015). How "situational" is judgment in situational judgment tests? Journal of Applied Psychology, $100(2), 399$.

Kuntz, J. R. C., Näswall, K., \& Malinen, S. (2016). Resilient employees in resilient organizations: Flourishing beyond adversity. Industrial And Organizational Psychology: Perspectives On Science And Practice, 9(2), 456-462.

Lamp, K. E. (2013). Personal and contextual resilience factors and their relations to psychological adjustment outcomes across the lifespan: A meta-analysis. (Unpublished Dissertation), Loyola University, Chicago, IL, ProQuest LLC. Retrieved from http://search.proquest.com/docview/1449402201?accountid=14745

Lee, E.-K. O., Shen, C., \& Tran, T. V. (2009). Coping with hurricane katrina: Psychological distress and resilience among african american evacuees. Journal of Black Psychology, 35, 5-23.

Lievens, F., De Corte, W., \& Schollaert, E. (2008). A closer look at the frame-of-reference effect in personality scale scores and validity. Journal of Applied Psychology, 93(2), 268.

Lovibond, S. H., \& Lovibond, P. F. (1995). Manual for the depression anxiety stress scales (2nd ed.). Sydney: The Psychology Foundation of Australia.

Luthans, F. (2002). The need for and meaning of positive organizational behavior. Journal of Organizational Behavior, 23, 695-706.

Luthans, F., Youssef, C. E., \& Avolio, B. J. (2007). Psychological capital: Developing the human competitive edge. New York, NY: Oxford University Press.

Luthar, S. S., Cicchetti, D., \& Becker, B. (2000). The construct of resilience: A critical evaluation and guidelines for future work. Child Development, 71, 543-562. 
Masten, A. S. (2001). Ordinary magic: Resilience processes in development. American Psychologist, 56(3), 227.

Mattson, M., \& Gibb-Hall, J. (2011). Health as communication nexus: A service learning approach (1 ed.). Dubuque, IA: Kendall Hunt Publishing.

McDaniel, M. A., Hartman, N. S., Whetzel, D. L., \& Grubb, W. (2007). Situational judgment tests, response instructions, and validity: A meta - analysis. Personnel Psychology, 60(1), 63-91.

McDaniel, M. A., Morgeson, F. P., Finnegan, E. B., Campion, M. A., \& Braverman, E. P. (2001). Use of situational judgment tests to predict job performance: A clarification of the literature. Journal of Applied Psychology, 86(4), 730-740.

McDaniel, M. A., \& Nguyen, N. T. (2001). Situational judgment tests: A review of practice and constructs assessed. International Journal of Selection and Assessment, 9, 103-113.

McLarnon, M. J. W., \& Rothstein, M. G. (2013). Development and initial validation of the workplace resilience inventory. Journal of Personnel Psychology, 12(2), 63-73.

Meredith, S., Sherbourne, C., Gaillot, S. J., Hansell, L., Ritschard, H. V., Parker, A. M., \& Wrenn, G. (2011). Promoting psychological resilience in the u.S. Military. Santa Monica, CA: RAND Corporation.

Mischel, W. (2009). From personality and assessment (1968) to personality science, 2009. Journal of Research in Personality, 43, 282-290.

Mischel, W., \& Shoda, Y. (1995). A cognitive-affective system theory of personality: Reconceptualizing situations, dispositions, dynamics, and invariance in personality structure. Psychological Review, 102(2), 246-268. 
Motowidlo, S. J., Dunnette, M. D., \& Carter, G. W. (1990). An alternative selection procedure: The low-fidelity simulation. Journal of Applied Psychology, 75(6), 640-647.

Motowidlo, S. J., Hooper, A. C., \& Jackson, H. L. (2006a). Implicit policies about relations between personality traits and behavioral effectiveness in situational judgment items. Journal of Applied Psychology, 91(4), 749-761.

Motowidlo, S. J., Hooper, A. C., \& Jackson, H. L. (2006b). A theoretical basis for situational judgment tests. In J. A. Weekley \& R. E. Ployhart (Eds.), Situational judgment tests: Theory, measurement and application. Mahwah, NJ: Erlbaum.

Nunnally, J. C. (1978). Psychometric theory (2 ed.). New York, NY: McGraw-Hill.

Nunnally, J. C., \& Bernstein, I. H. (1994). Psychometric theory (3 ed.). New York: McGrawHill.

Okun, M. A., Kardash, C. A., Stock, W. A., N., S. I., \& Baumann, D. J. (1986). Measuring perceptions of the quality of academic life among college students. Journal of College Student Personnel, 27, 447-451.

Pangallo, A. (2014). An exploration of the measurement of resilience in palliative care workers. (Ph.D. Unpublished Doctoral Thesis), City University London. Retrieved from http://openaccess.city.ac.uk/13710/

Pangallo, A., Zibarras, L. D., Lewis, R., \& Flaxman, P. (2015). Resilience through the lens of interactionism: A systematic review. Psychological Assessment, 27(1), 1-20.

Paterson, T. A., \& Harms, P. D. (2017). Too much of a good thing? Grit and the proliferation of positive constructs. Paper presented at the The 32nd Annual Conference of the Society for Industrial and Organizational Psychology, Orlando, FL. 
Ployhart, R. E., \& Holtz, B. C. (2008). The diversity-validity dilemma: Strategies for reducing racioethnic and sex subgroup differences and adverse impact in selection. Personnel Psychology, 61, 153-172.

Ployhart, R. E., \& MacKenzie Jr, W. I. (2011). Situational judgment tests: A critical review and agenda for the future. In S. Zedeck (Ed.), Apa handbook of industrial and organizational psychology: Selecting and developing members for the organization (Vol. 2, pp. 237 252). Washington, DC: American Psychological Association.

Rothstein, M. G., McLarnon, M. J. W., \& King, G. (2016). The role of self-regulation in workplace resiliency. Industrial And Organizational Psychology: Perspectives On Science And Practice, 9(2), 416-421.

Sackett, P. R., Borneman, M., \& Connelly, B. S. (2008). High stakes testing in education and employment: Evaluating common criticisms regarding validity and fairnes. American Psychologist, 63(4), 215-227.

Sameroff, A. J., \& Rosenblum, K. L. (2007). Psychosocial constraints on the development of resilience. Annals of the New York Academy of Sciences(1094), 116-124.

Sarkar, M., \& Fletcher, D. (2017). How resilience training can enhance wellbeing and performance. In M. F. Crane (Ed.), Managing for resilience: A practical guide for employee wellbeing and organizational performance (pp. 227-237). London, UK: Routledge.

Schaefer, C., Coyne, J. C., \& Lazarus, R. S. (1981). The health-related functions of social support. Journal of Behavioral Medicine, 4, 381-406. 
Seery, M. D., Holman, E. A., \& Silver, R. C. (2010). Whatever does not kill us: Cumulative lifetime adversity, vulnerability, and resilience. Journal of Personality and Social Psychology, 99(6), 1025-1041.

Shaffer, J. A., \& Postlethwaite, B. E. (2012). A matter of context: A meta-analytic investigation of the relative validity of contextualized and noncontextualized personality measures. Personnel Psychology, 65, 445-494.

Shaikh, A., \& Kauppi, C. (2010). Deconstructing resilience: Myriad conceptualizations and interpretations. International Journal of Arts and Sciences, 3(15), 155-176.

Sharma, S., Gangopadhyay, M., Austin, E., \& Mandal, M. K. (2013). Development and validation of a situational judgment test of emotional intelligence. International Journal of Selection and Assessment, 21(1), 57-73.

Shoenfelt, E. L. (2016). How much do we really know about employee resilience? More, if we include the sport psychology resilience research. Industrial And Organizational Psychology: Perspectives On Science And Practice, 9(2), 442-446.

Smith, B. W., Dalen, J., Wiggins, K., Tooley, E., Christopher, P., \& Bernard, J. (2008). The brief resilience scale: Assessing the ability to bounce back. International Journal of Behavioral Medicine, 15, 194-200.

Stanton, A. L., Kirk, S. B., Cameron, C. L., \& Danoff-Burg, S. (2000). Coping through emotional approach: Scale construction and validation. Journal of Personality and Social Psychology, 78, 1150-1169.

Tett, R. P., \& Burnett, D. D. (2003). A personality trait-based interactionist model of job performance. Journal of Applied Psychology, 88(3), 500-517. 
Tugade, M. M., \& Fredrickson, B. L. (2004). Resilient individuals use positive emotions to bounce back from negative emotional experiences. Journal of Personality and Social Psychology, 86(2), 320-333.

Tugade, M. M., Fredrickson, B. L., \& Barrett, L. F. (2004). Psychological resilience and positive emotional granularity: Examining the benefits of positive emotions on coping and health. Journal of Personality, 72(6), 1161-1190.

Vanderbilt-Adriance, E., \& Shaw, D. S. (2008). Conceptualizing and re-evaluating resilience across levels of risk, time, and domains of competence. Clinical Child Family Psychology Review, 11, 30-58.

Wagnild, G. M., \& Young, H. M. (1993). Development and psychometric evaluation of the resilience scale. Journal of Nursing Measurement, 1, 165-178.

Watson, D., Clark, L. A., \& Tellegen, A. (1988). Development and validation of brief measures of positive and negative affect: The panas scales. Journal of Personality and Social Psychology, 54, 1063-1070.

Weekley, J. A., Hawkes, B., Guenole, N., \& Ployhart, R. E. (2015). Low-fidelity simulations. Annual Review of Organizational Psychology and Organizational Behavior, 2(1), 295322.

Whetzel, D. L., \& McDaniel, M. A. (2009). Situational judgment tests: An overview of current research. Human Resource Management Review, 19(3), 188-202.

Windle, G. (2011). What is resilience? A review and concept analysis. Reviews in Clinical Gerontology, 21(2), 152-169.

Windle, G., Bennett, K. M., \& Noyes, J. (2011). A methodological review of resilience measurement scales. Health and Quality of Life Outcomes, 9(8), 1-18. 
Wolfson, N. E., \& Mulqueen, C. (2016). Advancing employee resilience research: Additional thoughts. Industrial And Organizational Psychology: Perspectives On Science And Practice, 9(2), 452-456. 
Table 1.

Item statistics (pilot test)

\begin{tabular}{|c|c|c|c|c|}
\hline Item & Mean & $S D$ & Corrected item-total Correlation & Alpha if item deleted \\
\hline 1 & 0.51 & 0.18 & 0.15 & 0.80 \\
\hline 2 & 0.72 & 0.26 & 0.31 & 0.79 \\
\hline 3 & 0.86 & 0.25 & 0.49 & 0.79 \\
\hline 4 & 0.96 & 0.37 & 0.38 & 0.79 \\
\hline 5 & 0.71 & 0.30 & 0.43 & 0.79 \\
\hline 6 & 0.99 & 0.43 & 0.35 & 0.80 \\
\hline 7 & 0.67 & 0.26 & 0.30 & 0.79 \\
\hline 8 & 0.42 & 0.12 & 0.29 & 0.79 \\
\hline 9 & 0.50 & 0.25 & 0.24 & 0.80 \\
\hline 10 & 0.71 & 0.23 & 0.39 & 0.79 \\
\hline 11 & 0.52 & 0.19 & 0.38 & 0.79 \\
\hline 12 & 1.16 & 0.43 & 0.29 & 0.80 \\
\hline 13 & 0.77 & 0.26 & 0.36 & 0.79 \\
\hline 14 & 0.73 & 0.37 & 0.15 & 0.80 \\
\hline 15 & 0.86 & 0.31 & 0.25 & 0.80 \\
\hline 16 & 0.91 & 0.31 & 0.35 & 0.79 \\
\hline 17 & 0.71 & 0.33 & 0.35 & 0.79 \\
\hline 18 & 0.78 & 0.35 & 0.32 & 0.79 \\
\hline 19 & 1.01 & 0.34 & 0.52 & 0.79 \\
\hline 20 & 0.52 & 0.20 & 0.42 & 0.79 \\
\hline 21 & 0.93 & 0.40 & 0.64 & 0.78 \\
\hline 22 & 0.59 & 0.22 & 0.54 & 0.79 \\
\hline 23 & 0.66 & 0.29 & 0.46 & 0.79 \\
\hline 24 & 0.64 & 0.21 & 0.37 & 0.79 \\
\hline 25 & 0.64 & 0.27 & 0.34 & 0.79 \\
\hline 26 & 0.49 & 0.09 & 0.48 & 0.79 \\
\hline 27 & 0.63 & 0.27 & 0.13 & 0.80 \\
\hline 28 & 0.70 & 0.15 & 0.11 & 0.80 \\
\hline 29 & 0.51 & 0.16 & -0.01 & 0.80 \\
\hline 30 & 0.49 & 0.21 & 0.11 & 0.80 \\
\hline 31 & 0.56 & 0.16 & 0.17 & 0.80 \\
\hline 32 & 0.59 & 0.36 & 0.29 & 0.80 \\
\hline 33 & 0.56 & 0.21 & 0.56 & 0.79 \\
\hline 34 & 0.67 & 0.27 & 0.36 & 0.79 \\
\hline 35 & 0.47 & 0.13 & 0.22 & 0.80 \\
\hline 36 & 0.53 & 0.12 & 0.39 & 0.79 \\
\hline 37 & 0.68 & 0.30 & 0.60 & 0.78 \\
\hline 38 & 0.96 & 0.47 & 0.45 & 0.79 \\
\hline 39 & 0.81 & 0.29 & 0.45 & 0.79 \\
\hline 40 & 0.75 & 0.28 & 0.28 & 0.80 \\
\hline
\end{tabular}


Table 2.

Item statistics (main study)

\begin{tabular}{|c|c|c|c|c|}
\hline Item & Mean & $S D$ & Corrected item-total Correlation & Alpha if item deleted \\
\hline 1 & 0.50 & 0.19 & 0.20 & 0.86 \\
\hline 2 & 0.67 & 0.25 & 0.34 & 0.86 \\
\hline 3 & 0.84 & 0.28 & 0.47 & 0.86 \\
\hline 4 & 0.95 & 0.38 & 0.35 & 0.86 \\
\hline 5 & 0.71 & 0.31 & 0.44 & 0.86 \\
\hline 6 & 0.92 & 0.45 & 0.55 & 0.86 \\
\hline 7 & 0.71 & 0.29 & 0.34 & 0.86 \\
\hline 8 & 0.41 & 0.12 & 0.26 & 0.86 \\
\hline 9 & 0.54 & 0.25 & 0.30 & 0.86 \\
\hline 10 & 0.68 & 0.24 & 0.43 & 0.86 \\
\hline 11 & 0.53 & 0.19 & 0.23 & 0.86 \\
\hline 12 & 1.04 & 0.52 & 0.46 & 0.86 \\
\hline 13 & 0.71 & 0.29 & 0.45 & 0.86 \\
\hline 14 & 0.73 & 0.39 & 0.48 & 0.86 \\
\hline 15 & 0.82 & 0.35 & 0.49 & 0.86 \\
\hline 16 & 0.88 & 0.33 & 0.45 & 0.86 \\
\hline 17 & 0.62 & 0.33 & 0.49 & 0.86 \\
\hline 18 & 0.85 & 0.32 & 0.41 & 0.86 \\
\hline 19 & 0.91 & 0.37 & 0.59 & 0.85 \\
\hline 20 & 0.53 & 0.22 & 0.29 & 0.86 \\
\hline 21 & 0.82 & 0.43 & 0.39 & 0.86 \\
\hline 22 & 0.58 & 0.23 & 0.57 & 0.86 \\
\hline 23 & 0.67 & 0.29 & 0.41 & 0.86 \\
\hline 24 & 0.61 & 0.23 & 0.49 & 0.86 \\
\hline 25 & 0.58 & 0.29 & 0.32 & 0.86 \\
\hline 26 & 0.49 & 0.10 & 0.26 & 0.86 \\
\hline 27 & 0.66 & 0.29 & 0.47 & 0.86 \\
\hline 28 & 0.53 & 0.23 & 0.33 & 0.86 \\
\hline 29 & 0.51 & 0.15 & 0.28 & 0.86 \\
\hline 30 & 0.38 & 0.08 & 0.19 & 0.86 \\
\hline 31 & 0.55 & 0.17 & 0.32 & 0.86 \\
\hline 32 & 0.62 & 0.36 & 0.36 & 0.86 \\
\hline 33 & 0.58 & 0.21 & 0.53 & 0.86 \\
\hline 34 & 0.66 & 0.29 & 0.40 & 0.86 \\
\hline 35 & 0.49 & 0.17 & 0.33 & 0.86 \\
\hline 36 & 0.51 & 0.14 & 0.20 & 0.86 \\
\hline 37 & 0.67 & 0.30 & 0.47 & 0.86 \\
\hline 38 & 0.98 & 0.50 & 0.49 & 0.86 \\
\hline 39 & 0.75 & 0.39 & 0.55 & 0.85 \\
\hline 40 & 0.69 & 0.29 & 0.45 & 0.86 \\
\hline
\end{tabular}


Table 3.

Descriptive statistics and bivariate correlations for variables

\begin{tabular}{lrrcccccc}
\hline & Mean & \multicolumn{1}{c}{ SD } & 1 & 2 & 3 & 4 & 5 & 6 \\
\hline 1. SJT & 0.67 & 0.12 & $(.86)$ & & & & & \\
2. Hardiness & 29.16 & 6.00 & $.42 * * *$ & $(.77)$ & & & & \\
3. CD-RISC & 70.39 & 16.09 & $.32 * * *$ & $.70 * * *$ & $(.94)$ & & & \\
4. 5×5 RS & 3.51 & 0.59 & $.43 * * *$ & $.72 * * *$ & $.65 * * *$ & $(.90)$ & & \\
5. Positive affect & 3.43 & 0.93 & .13 & $.57 * * *$ & $.60 * * *$ & $.54 * * *$ & $(.93)$ & \\
6. Negative affect & 2.29 & 0.82 & $-.40 * * *$ & $-.47 * * *$ & $-.34 * * *$ & $-.60 * * *$ & -.12 & $(.89)$ \\
7. Adaptability & 3.56 & 0.76 & $.33 * * *$ & $.57 * * *$ & $.48 * * *$ & $.69 * * *$ & $.38^{* * *}$ & $-.29 * * *$ \\
8. Emotion regulation & 2.84 & 0.87 & .11 & $.23 * * *$ & $.23 * * *$ & $.55 * * *$ & $.17 * *$ & $-.34 * * *$ \\
9. Optimism & 3.63 & 0.98 & $.40^{* * *}$ & $.63 * * *$ & $.52 * * *$ & $.81 * * *$ & $.46 * * *$ & $-.65 * * *$ \\
10. Self-efficacy & 3.88 & 0.70 & $.31 * * *$ & $.53 * * *$ & $.65 * * *$ & $.73 * * *$ & $.49 * * *$ & $-.35 * * *$ \\
11. Social Support & 3.62 & 0.85 & $.36 * * *$ & $.57 * * *$ & $.46 * * *$ & $.76 * * *$ & $.43 * * *$ & $-.46 * * *$ \\
12. Satisfaction & 25.84 & 6.61 & .13 & $.45 * * *$ & $.51 * * *$ & $.41 * * *$ & $.49 * * *$ & $-.27 * * *$ \\
13. Depression & 5.20 & 5.24 & $-.47 * * *$ & $-.55 * * *$ & $-.47 * * *$ & $-.63 * * *$ & $-.36 * * *$ & $.67 * * *$ \\
14. Stress & 6.74 & 4.79 & $-.42 * * *$ & $-.43 * * *$ & $-.34 * * *$ & $-.60 * * *$ & $-.21 * * *$ & $.68 * * *$ \\
15. Anxiety & 5.25 & 5.16 & $-.46 * * *$ & $-.39 * * *$ & $-.30 * * *$ & $-.55 * * *$ & $-.14 *$ & $.64 * * *$ \\
16. Cumulative GPA & 3.33 & 0.48 & .12 & -.03 & $.19 * *$ & .07 & .06 & -.08 \\
\hline
\end{tabular}

Notes. $N=193-211 .{ }^{* * *} p<.001 ; * * p<.01 ; * p<.05$ 


\begin{tabular}{llllllllll}
\hline 7 & 8 & 9 & 10 & 11 & 12 & 13 & 14 & 15 & 16 \\
\hline
\end{tabular}

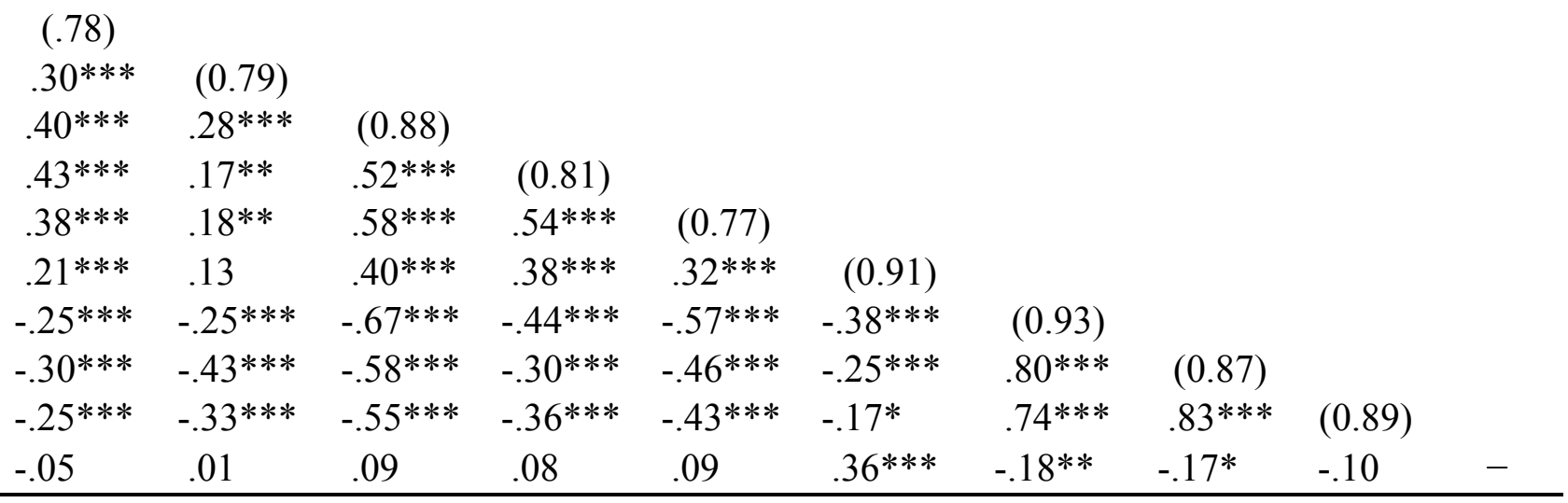


Table 4.

Discriminant Validity of the Resilience SJT

\begin{tabular}{|c|c|c|c|c|c|}
\hline Variable & $B$ & $\beta$ & $S E$ & $t$ & $p$ \\
\hline & \multicolumn{5}{|c|}{ SJT } \\
\hline Intercept & 0.59 & 0.00 & 0.05 & 10.82 & $<.001$ \\
\hline Hardiness & 0.01 & 0.37 & 0.00 & 4.33 & $<.001$ \\
\hline $\mathrm{PA}$ & -0.01 & -0.11 & 0.01 & -1.45 & .15 \\
\hline NA & -0.03 & -0.24 & 0.01 & -3.42 & $<.001$ \\
\hline$R^{2}(\operatorname{adj})$ & \multicolumn{5}{|c|}{$0.24(0.23)$} \\
\hline \multirow[t]{2}{*}{$F$} & \multicolumn{4}{|c|}{$F(3,207)=21.32$} & $<.001$ \\
\hline & \multicolumn{5}{|c|}{ CD-RISC } \\
\hline Intercept & 16.74 & 0.00 & 5.62 & 2.98 & $<.01$ \\
\hline Hardiness & 1.31 & 0.49 & 0.17 & 7.56 & $<.001$ \\
\hline PA & 5.49 & 0.32 & -1.00 & 5.51 & $<.001$ \\
\hline NA & -1.46 & -0.07 & -1.05 & -1.40 & .16 \\
\hline$R^{2}(\operatorname{adj})$ & \multicolumn{5}{|c|}{$0.56(0.55)$} \\
\hline \multirow[t]{2}{*}{$F$} & \multicolumn{4}{|c|}{$F(3,207)=87.82$} & $<.001$ \\
\hline & \multicolumn{5}{|c|}{$5 \times 5 \mathrm{RS}$} \\
\hline Intercept & 2.50 & 0.00 & 0.18 & 13.76 & $<.001$ \\
\hline Hardiness & 0.04 & 0.36 & 0.01 & 6.38 & $<.001$ \\
\hline PA & 0.18 & 0.29 & 0.03 & 5.68 & $<.001$ \\
\hline NA & -0.29 & -0.40 & 0.03 & -8.55 & $<.001$ \\
\hline$R^{2}(\operatorname{adj})$ & \multicolumn{5}{|c|}{$0.66(0.65)$} \\
\hline$F$ & \multicolumn{4}{|c|}{$F(3,207)=133.00$} & $<.001$ \\
\hline
\end{tabular}

Notes. $N=209 ; \mathrm{PA}=$ Positive Affect, $\mathrm{NA}=$ Negative Affect; values in parentheses are adjusted $R^{2}$ s. 
Table 5.

Incremental validity of the Resilience SJT in predicting college satisfaction

\begin{tabular}{|c|c|c|c|c|c|c|c|}
\hline \multirow[b]{2}{*}{ Variable } & \multicolumn{7}{|c|}{ College Satisfaction } \\
\hline & $B$ & $\beta$ & $S E$ & $p$ & $R^{2}$ (adj.) & $F$ & $p$ \\
\hline Step 1 & & & & & $0.27(0.26)$ & $F(2,208)=38.64$ & $<.001$ \\
\hline Intercept & 8.44 & 0.00 & 2.37 & $<.001$ & & & \\
\hline CD-RISC & 0.18 & 0.43 & 0.03 & $<.001$ & & & \\
\hline $5 \times 5 \mathrm{RS}$ & 1.44 & 0.13 & 0.88 & .10 & & & \\
\hline Step 2 & & & & & $0.28(0.27)$ & $F(3,207)=26.32$ & $<.001$ \\
\hline Intercept & 10.09 & 0.00 & 2.73 & $<.001$ & & & \\
\hline CD-RISC & 0.18 & 0.43 & 0.03 & $<.001$ & & & \\
\hline $5 \times 5 \mathrm{RS}$ & 1.78 & 0.16 & 0.92 & .05 & & & \\
\hline SJT & -4.48 & -0.08 & 3.67 & .22 & & & \\
\hline$\Delta R^{2}$ & & & & & 0.01 & $F(1,207)=1.49$ & .22 \\
\hline
\end{tabular}

Notes. $N=209$; values in parentheses are adjusted $R^{2}$ s. 
Table 6.

Incremental validity of the Resilience SJT in predicting depression

\begin{tabular}{|c|c|c|c|c|c|c|c|}
\hline \multirow[b]{2}{*}{ Variable } & \multicolumn{7}{|c|}{ Global Adjustment - Depression } \\
\hline & $B$ & $\beta$ & $S E$ & $p$ & $R^{2}$ (adj.) & $F$ & $p$ \\
\hline Step 1 & & & & & $0.47(0.47)$ & $F(2,208)=92.95$ & $<.001$ \\
\hline Intercept & 5.44 & 0.00 & 0.30 & $<.001$ & & & \\
\hline CD-RISC & -0.01 & -0.16 & 0.00 & .02 & & & \\
\hline $5 \times 5 \mathrm{RS}$ & -0.96 & -0.57 & 0.11 & $<.001$ & & & \\
\hline Step 2 & & & & & $0.50(0.49)$ & $F(3,207)=69.32$ & $<.001$ \\
\hline Intercept & 6.02 & 0.00 & 0.34 & $<.001$ & & & \\
\hline CD-RISC & -0.01 & -0.14 & 0.00 & .03 & & & \\
\hline $5 \times 5 \mathrm{RS}$ & -0.84 & -0.50 & 0.11 & $<.001$ & & & \\
\hline SJT & -1.58 & -0.19 & 0.45 & $<.001$ & & & \\
\hline$\Delta R^{2}$ & & & & & 0.05 & $F(1,207)=12.13$ & $<.001$ \\
\hline
\end{tabular}

Notes. $N=209$; values in parentheses are adjusted $R^{2} \mathrm{~s}$; after log-transformation. 
Table 7.

Incremental validity of the Resilience SJT in predicting anxiety

\begin{tabular}{rrrrcccc}
\hline & \multicolumn{7}{c}{ Global Adjustment - Anxiety } \\
\cline { 2 - 8 } Variable & \multicolumn{1}{c}{$B$} & $\beta$ & $S E$ & $p$ & $R^{2}$ (adj.) & $F$ & $p$ \\
\hline Step 1 & & & & & $0.31(0.30)$ & $F(2,208)=46.43$ & $<.001$ \\
Intercept & 21.87 & 0.00 & 1.80 & $<.001$ & & \\
CD-RISC & 0.03 & 0.10 & 0.02 & .20 & & \\
5×5 RS & -5.38 & -0.61 & 0.67 & $<.001$ & & & \\
& & & & & & & \\
Step 2 & & & & & $0.37(0.36)$ & $F(3,207)=40.98$ & \\
Intercept & 26.39 & 0.00 & 1.98 & $<.001$ & & & \\
CD-RISC & 0.04 & 0.12 & 0.02 & .10 & & & \\
5×5 RS & -4.45 & -0.51 & 0.67 & $<.001$ & & & \\
SJT & -12.24 & -0.28 & 2.66 & $<.001$ & & & \\
$\Delta R^{2}$ & & & & & & & \\
\end{tabular}

Notes. $N=209$; values in parentheses are adjusted $R^{2}$ s. 
Table 8 .

Incremental validity of the Resilience SJT in predicting stress

\begin{tabular}{|c|c|c|c|c|c|c|c|}
\hline \multirow[b]{2}{*}{ Variable } & \multicolumn{7}{|c|}{ Global Adjustment - Stress } \\
\hline & $B$ & $\beta$ & $S E$ & $p$ & $R^{2}$ (adj.) & $F$ & $p$ \\
\hline Step 1 & & & & & $0.37(0.36)$ & $F(2,208)=60.04$ & $<.001$ \\
\hline Intercept & 23.60 & 0.00 & 1.60 & $<.001$ & & & \\
\hline CD-RISC & 0.03 & 0.10 & 0.02 & .18 & & & \\
\hline $5 \times 5 \mathrm{RS}$ & -5.40 & -0.66 & 0.59 & $<.001$ & & & \\
\hline Step 2 & & & & & $0.40(0.39)$ & $F(3,207)=46.13$ & $<.001$ \\
\hline Intercept & 26.69 & 0.00 & 1.80 & $<.001$ & & & \\
\hline CD-RISC & 0.03 & 0.11 & 0.02 & .11 & & & \\
\hline $5 \times 5 \mathrm{RS}$ & -4.76 & -0.59 & 0.60 & $<.001$ & & & \\
\hline SJT & -8.36 & -0.21 & 2.42 & $<.001$ & & & \\
\hline$\Delta R^{2}$ & & & & & 0.03 & $F(1,207)=11.98$ & $<.001$ \\
\hline
\end{tabular}

Notes. $N=209$; values in parentheses are adjusted $R^{2}$ s. 
Table 9.

Incremental validity of the Resilience SJT in predicting cumulative GPA

\begin{tabular}{|c|c|c|c|c|c|c|c|}
\hline \multirow[b]{2}{*}{ Variable } & \multicolumn{7}{|c|}{ Cumulative GPA } \\
\hline & $B$ & $\beta$ & $S E$ & $p$ & $R^{2}$ (adj.) & $F$ & $p$ \\
\hline Step 1 & & & & & $0.04(0.03)$ & $F(2,190)=4.21$ & .02 \\
\hline Intercept & 3.07 & 0.00 & 0.21 & $<.001$ & & & \\
\hline CD-RISC & 0.01 & 0.25 & 0.00 & .01 & & & \\
\hline $5 \times 5 \mathrm{RS}$ & -0.07 & -0.09 & 0.08 & .34 & & & \\
\hline Step 2 & & & & & $0.05(0.04)$ & $F(3,189)=3.43$ & .02 \\
\hline Intercept & 2.90 & 0.00 & 0.24 & $<.001$ & & & \\
\hline CD-RISC & 0.01 & 0.24 & 0.00 & .01 & & & \\
\hline $5 \times 5 \mathrm{RS}$ & -0.11 & -0.13 & 0.08 & .18 & & & \\
\hline SJT & 0.45 & 0.11 & 0.33 & .18 & & & \\
\hline$\Delta R^{2}$ & & & & & 0.01 & $F(1,189)=1.83$ & .18 \\
\hline
\end{tabular}

Notes. $N=191$; values in parentheses are adjusted $R^{2}$ s. 
Table 10.

Construct validity correlations of the SJT Resilience mode scores

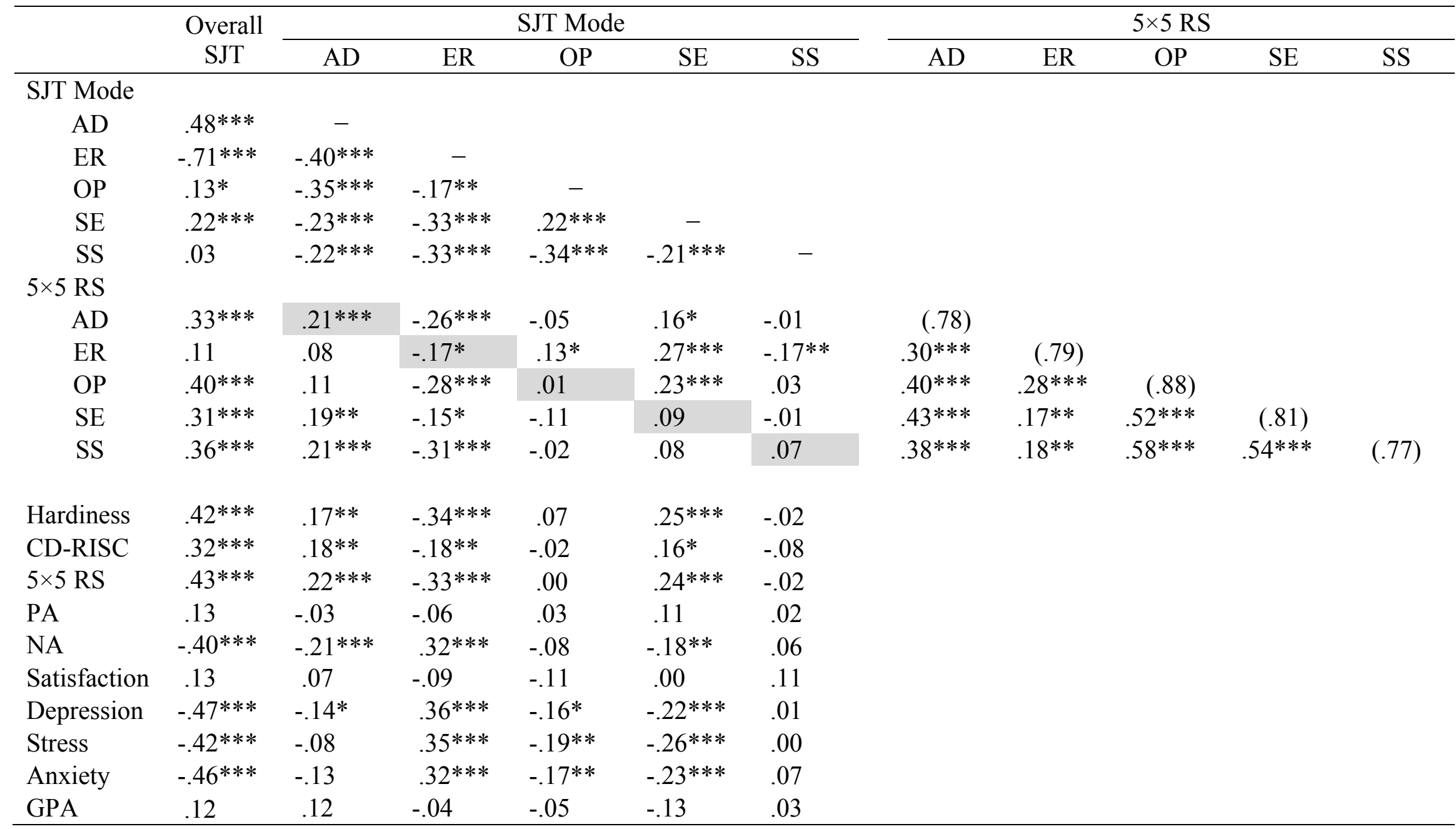

Notes. $N=193-211 ; \mathrm{PA}=$ Positive Affect, $\mathrm{NA}=$ Negative Affect, $\mathrm{AD}=$ Adaptability, $\mathrm{ER}=$ Emotion Regulation, $\mathrm{OP}=\mathrm{Optimism}, \mathrm{SE}$ $=$ Self-efficacy, $\mathrm{SS}=$ Social Support; correlations in grey represent convergent validity coefficients (mono-trait hetero-method).

$* * * p<.001 ; * * p<.01 ; * p<.05$ 


\section{Appendix A:}

\section{Finalized Resilience SJT Items}

In the following section of the study, you will be presented with a series of hypothetical scenarios and their response alternatives. For each situational scenario, please indicate your most likely and least likely responses in corresponding columns. Please note that there is no right or wrong answer.

1. A good friend of yours has a new significant other. Lately this friend has been cancelling plans to meet you in order to spend time with their new love. After meeting for lunch one day, your friend tells you they miss spending time with you and apologizes for not being able to see you as much. You make plans, but your friend cancels again at the last minute and explains they are going with their significant other on a romantic getaway. What would you most likely do? What would you least likely do?

A. Let your friend know that you are done making plans with him/her

B. Call a friend to explain what has been going on and ask for advice about what to do

C. Remind yourself to be happy for your love-struck friend and expect that eventually you'll be close again

D. Make an effort to plan around his/her schedule

E. Tell yourself you can handle this situation; you've handled worse

2. You have accepted a scholarship to play a sport at your dream school. During your first semester, it turns out that the school and team are not what you expected; in fact, you are quite disappointed. You are having trouble adjusting to the college experience and are struggling in your classes. What would you most likely do? What would you least likely do?

A. Tell yourself that you cannot balance being a student and an athlete at the same time

B. Tell yourself that a bad semester is ok and that next semester things will work out

C. Decide to withdraw either from the school, the team, or both

D. Talk to your parents and peers about your feelings about the current situation

E. Simply accept that this is what college is going to be like and carry on

3. Imagine that you have accepted an internship with a Fortune 500 company. Your position requires a great deal of financial knowledge and skills beyond your current abilities. Despite your efforts, you have missed multiple deadlines, and your supervisor warns you that missing deadlines cannot continue. What would you most likely do? What would you least likely do?

A. Explain to your supervisor that it's not your fault

B. Use your free time to learn what is necessary to complete your tasks

C. Expect that it's probably not going to get better and that you are going to get fired

D. Take some time to decompress and give yourself a break

E. Consult with fellow co-workers and ask what they do to stay on top of things 
4. As you are working at the register at Starbucks on a Monday morning, your current customer is ordering several cups of coffee for her coworkers and the line is backed up. The person behind her starts yelling, "Why is it taking so long? Get me another person to take the order! I am late for work!" What would you most likely do? What would you least likely do?

A. Put your current task down and take his order instead so that he will not complain

B. Get the barista at the espresso station to take that customer's order

C. Tell him nicely, "Just one moment. I will be right with you"

D. Remind yourself that it's just one customer; today will still turn out great

E. Finish your current order and then go on break

5. As a law student in a prestigious law school, you are under intense pressure and doing your utmost to get ahead of your peers. At the end of your first year in law school, you got your annual ranking and you learned that you were ranked at the bottom 30th percentile. What would you most likely do? What would you least likely do?

A. Contact your peers and form a study group

B. Call your friends to decompress

C. Give up an additional 2 hours of sleep so you can spend more time studying

D. Decide that pursuing a J.D. degree is not for you and change your career path

E. Realize that it is just your first year; things will work out well in the end

6. You are taking an upper level physics class to fulfill a college major requirement. It is one of the hardest courses you have taken and is regarded as a good indicator of future career success. Halfway through the semester, you have completed two course projects and you got C's for both. What would you most likely do? What would you least likely do?

A. Tell yourself that you will do well in the end because you are smart and hard-working

B. Go to your professor to ask for feedback and study accordingly

C. Decide to switch to a less demanding field since you do not perform well in this one

D. Tell yourself that this is just a minor setback and things will turn out well in the end

E. Talk to other students in your class for support

7. You graduated from college summa cum laude with a degree in anthropology. You have always wanted to become a curator. However, after two years after your graduation, you have yet to find such a job. To make ends meet, you have been working at a call center for the past two years. Finally you get an interview for your dream job. At the interview, your interviewer says, "you have a really impressive transcript but you don't have any working experience. I am sorry that we cannot hire someone who's been working at a call center for two years." What would you most likely do? What would you least likely do?

A. You know that the bad job market and current economy is what makes job-hunting harder and you'll get your dream job once the economy recovers

B. Volunteer at museums to get unpaid experience

C. Go back to school to get an advanced degree in anthropology

D. Join a professional network of museum workers to look for support and opportunities

E. Talk to your best friend about your frustration and defeat 
8. Imagine that you love playing basketball and have always wanted to become a professional basketball player. Right before the most important game in your life, you get involved in a terrible car accident and become paralyzed from the waist down. Your doctor informs you that it would be unlikely that you would be able to walk again. What would you most likely do? What would you least likely do?

A. Tell yourself that doctors are wrong sometimes and that you will eventually restore your ability to walk and play basketball

B. Join a support group to deal with physical and psychological difficulties you have after the accident

C. Keep yourself from getting your hopes up due to the low recovery rate

D. Keep to yourself while you come to terms with your diagnosis

E. Remind yourself of the times when you beat the odds and believe you will walk again if you work hard

F. Believe that this is one of the challenges God has given you and you can get through it with God's guidance

9. You have been dating someone and think things are going well. But at dinner, they say, "Things are not working out. I'd like to break up." Upon hearing the bad news (breakup), what thought would be most likely to cross your mind? What thought would be least likely to cross your mind?

A. "Nobody will love me. I am going to die alone."

B. "Plenty of fish in the sea. I will find the right person eventually."

C. "Relationships are not for me. I'm so done with relationships."

D. "I am not alone in this. I am going to call my best friend to talk about it."

E. "I am just going to take a break from dating and focus on myself for a while."

F. "It is all my fault. I was a terrible girlfriend/boyfriend. I don't deserve love."

G. "It is not a big deal. I have seen relationships end before. I will get over this eventually."

10. While in law school, you accepted an internship at a large law firm. Your immediate supervisor is known for screaming at subordinates. He frequently criticizes your work, suggesting that you are incompetent. What would you most likely do? What would you least likely do?

A. Fire back and tell him what a terrible boss he is

B. Ask for advice from your friends on how to deal with your boss's criticisms

C. Vent to your significant other about your boss after work

D. Ignore your boss's mean language and use his criticisms to improve your work

E. Switch to a different department or company since your boss is making you miserable

F. Take his words to heart and think that you are truly as stupid and incompetent as he says

11. You are diagnosed with a rare degenerative disease that results in frequent doctor visits, a major change in your lifestyle, and eventually confinement to a wheel chair. What would you most likely do? What would you least likely do?

A. Seek out a support group that consists of similar circumstances

B. Pray and seek guidance from your religion

C. Ruminate on your feelings and wonder why this is happening to you

D. Keep the diagnosis to yourself and try to get through this alone 
E. Tell yourself that there is a silver lining in every situation and good things will happen

12. You are running late to a job interview. It is crucial that you are on time, but you get stuck in traffic. To make matters worse, a pick up truck has just cut you off. What would you most likely do? What would you least likely do?

A. Tell yourself that your employer will understand your tardiness

B. Get out of your car and confront the driver

C. Take a deep breath and regulate your anger

D. Accept being late and inform your potential employer

E. Drive more aggressively in order to make it on time

13. You have recently moved into an apartment with some friends and one of them consistently leaves dirty dishes scattered around. You also notice that he drops food on the counter and floor and he does not clean after himself. As a result, roaches begin to appear. What would you most likely do? What would you least likely do?

A. Clean up after him

B. Sit down with him and make sure he does his part in cleaning

C. Talk to your other roommates about it separately and see what they have to say

D. Stop cleaning up after yourself and let the apartment get even dirtier

E. Simply hope that he will begin to clean up more after seeing the roaches

F. Tell yourself that you've dealt with roommates like him before and you will get him to stop in your own way

14. While driving home from school during rush hour, you are stuck in the left lane behind someone driving slowly. What would you most likely do? What would you least likely do?

A. Call a close friend and vent about the situation

B. Lay on your horn, yell, and let the tension out freely

C. Think that this was bound to happen because bad things always happen you

D. Check your phone and make a social media post about your bad luck

E. Tell yourself that its just not your day but things will get better

15. Imagine that your best friend, whom you had known since you were little, got into a terrible car accident and was in critical condition. Despite doctors' great effort and your daily visits, he/she passed away. What would you most likely do? What would you least likely do?

A. Go to a support group to deal with loss of loved ones

B. Realize that if that happened to your friend, that could happen to you too

C. Drown your sorrows with alcohol to forget what happened

D. Realize that life is short and your friend would have wanted you to carry on

E. Tell yourself that you can get through this even though it will be hard

16. Imagine that it is almost midnight and you will have an important class presentation the next day. You are trying to get a good night's sleep because you must be at your best for the presentation. Just when your head hits the pillow, loud music starts blasting from next door. You are struggling to fall asleep for almost an hour but without any success. What would you most likely do? What would you least likely do?

A. Egg your neighbor's door to get back at him/her to release your anger 
B. Use the opportunity to get something done since you are up

C. Call your other neighbor(s) and ask if they are disturbed as well

D. Tell yourself that they'll turn it down soon

E. Use a sleep-aid in order to help you sleep through the noise

17. Your professor asks you to write a proposal for a course project. After getting the details, you spend a considerable amount of time researching and writing after hours. When you give the report to your professor on Monday, it comes back with red pen everywhere, and it's clear your professor changed the direction of the project without telling you. To make matters worse, he expects the new proposal in two days. What would you most likely do? What would you least likely do?

A. Immediately get to work on the new direction, expecting to work late

B. Pray for guidance in how to proceed

C. Call a friend to vent

D. Enlist the aid of one of your peers to help with part of the proposal

E. Tell yourself that you are really good at this and that you will be able to do a good job

18. Your drinking habits become more frequent and it has begun to take a toll on your schoolwork and your personal life. Some of your family and friends have expressed their concern with your behaviors. You have tried to cut back, but your efforts have always gone in vain. What would you most likely do? What would you least likely do?

A. Continue drinking as if you don't have a drinking problem

B. Stop talking to the people who have approached you about your drinking problem

C. Try to find a hobby that will pacify your urges to drink

D. Think that this issue has become hopeless because you've tried and failed

E. Tell yourself that you are capable of cutting it back

19. You are a student tutor to help college students with their math courses. One day, you are tutoring a student with her/his Calculus II homework and suddenly s/he starts yelling at you, "You don't know what you are talking about! I have been excellent in math since high school and I got an 800 on my math SAT. What you are saying doesn't make any sense! How did you become a math tutor in the first place?!" What would you most likely do? What would you least likely do?

A. Feel offended and yell back at him/her

B. Be polite, and ask your supervisor to assign you to a different student afterwards

C. Ask your student if s/he would prefer to work with someone else

D. Ask other tutors how to best handle this kind of situation

E. Search online for how to best handle this kind of situation after the meeting

20. You are working part-time to support yourself through college. One day you are called to your supervisor's office. Your supervisor surprises you by saying, "I am sorry to inform you that the company is restructuring and your job has been eliminated. You have been let go." What would you most likely do? What would you least likely do?

A. Tell yourself that you are competent to land a similar job and accept the termination

B. Hide your emotions and exit your boss's office politely

C. Figure that getting fired is an opportunity to explore other career options. 
D. Call someone close to you to vent your frustrations once you leave.

E. Update your resume and look for another job right away

21. One morning, you get out of bed and remember that you got fired yesterday. What would you most likely do? What would you least likely do?

A. Call your friends and tell them you are looking for a job

B. Make a plan for job hunting

C. Cancel any plans that involve spending

D. Recall a time when your chips were down and tell yourself that you'll be able to handle it

E. Go to church and pray in the hope that God will help you through difficult times

22. You got admitted to an Ivy League school but it required you to move from a small town to a big city. Three months has passed and you are still having a hard time adjusting to big city life. Without any friends in the new city, you often feel lonely and lost. To make things worse, it is really hard for you to get used to the new competitive academic environment and college life and you fail to get along with the city people and make any new friends. What would you most likely do? What would you least likely do?

A. Decide it is time to move back to your hometown and transfer to a school there

B. Join a club for freshmen to make friends and connections

C. Pay more attention to how big city people behave, and then adopt their mannerisms and values in order to fit in

D. Ignore big city people because you know they are jerks and not worth your effort

E. Tell yourself that this is just an obstacle to overcome to lead the life you want

F. Go to a local online forum and ask for advice on how to adjust to college and the city life

23. A month into interning for a consulting firm, you realize that your assignment is far different from what you expected. You want higher-level projects and more responsibilities, but your boss only assigns you to do coffee runs and take care of entry-level work. What would you most likely do? What would you least likely do?

A. Accept the entry-level work but work extra projects when you have a chance

B. Keep doing whatever is assigned because this is just how it is for an intern

C. Talk to your boss and explain that what you are assigned to do is too basic for your skills

D. Ask senior colleagues for advice on how to take on projects you would like

E. Decide that this position is a waste of your time and talent and resign

F. Tell yourself that this is a warming-up period and you'll have higher-level projects soon

24. Imagine you are leading a team to compete for a $\$ 10,000$ scholarship that supports young entrepreneurs to start up their own businesses. You are competing against nine other teams and only one team will be selected. Despite months of hard work and late hours, your team has lost. What would you most likely do? What would you least likely do?

A. Figure out what made your application fall short and make up for it next time

B. Feel discouraged and frustrated and go to a bar to blow off steam

C. Take the loss hard and shut people out when they ask you if there is anything wrong

D. Tell yourself that you are an excellent entrepreneur and you will get it next time

E. Hold an emergency meeting with your team and find someone to blame for the failure

F. Share your feelings with your significant other who has always believed in you 
25. Imagine that you found a summer job for a company that sells and installs replacement windows to homeowners. The job pays mostly on commission (a percentage of sales). After a week of house calls and phone calls, you have not sold any windows. What would you most likely do? What would you least likely do?
A. Look for another job
B. Remind you yourself that you can do this and keep on plugging
C. Pray for guidance
D. Ask a coworker for tips on sales
E. See your failures as learning opportunities

26. You are assigned to a group and asked to take the leadership to work on a group project for one of your classes. One of your teammates is always late to your group meetings and rarely finishes work on time. When she does finish her work, it is always of poor quality. You try to ask your professor to assign you to a different team but your professor is reluctant to do so. What would you most likely do? What would you least likely do?

A. Tell this teammate to shape up or ship out

B. Continue with this teammate because you know you have great leadership skills

C. Ask your peers for ideas on how to deal with the teammate

D. Tell you friends how this teammate would ruin your group project

E. Look at this situation as an opportunity to enhance your interpersonal skills

27. Imagine you were a passenger in a car crash that has injured your pelvis, right hip, and right leg. The doctors have told you that you would be unlikely to regain full use of your leg, and probably would never be able to walk. You have been confined to a wheel chair for the last three months while undergoing physical therapy and trying to walk. Although you can put some weight on your right leg, it won't support you and you have not been able to walk. What would you most likely do? What would you least likely do?
A. Accept that you are confined to a wheelchair for now
B. Remind yourself that you've overcome many challenges and continue to work on walking
C. Maintain your spiritual beliefs, trusting that things will work out the way that they are supposed to
D. Join a support group of other car crash victims to share your feelings
E. Level with yourself that the road ahead will be long and frustrating

28. Imagine that you are a Pre-Med student. You took Organic Chemistry for the first time and flunked it. Today your advisor suggested that you find a different major. What would you most likely do? What would you least likely do?
A. Find another major that better suits your talents and interests
B. Ask your professor about how to study
C. Talk it over with your friends
D. Go to church and pray for guidance
E. Tell yourself that no matter what happens, things will work out for the best 
29. Suppose that you have been having car troubles and you take it to the dealer because you believe the problem is covered by a warranty. The dealer calls to tell you that a malfunctioning electronic starter was replaced. When you get to the dealership, the service manager tells you that the repair was not covered by your warranty so you owe $\$ 750.00$. What would you most likely do? What would you least likely do?

A. Get your lawyer involved to resolve the issue

B. Remind yourself of times when you've won in the end, and dispute the decision later

C. Pay and take in a movie to forget about it

D. Tell yourself that you are not good at arguing and so you pay to get it over with

E. Tell yourself that it is not totally bad; it could've been more expensive

30. You loan one of your roommates $\$ 500$. S/he has a good job and should have the money to pay you back. Instead of keeping the repayment schedule you both agreed to, some months s/he only pay half, and other months nothing at all. What would you most likely do? What would you least likely do?

A. Get other roommates involved and stage an intervention

B. Tell your roommate that you've had it and lay into him/her

C. Remind yourself of times when you've had difficult conversations and confront him/her

D. Vent to someone close to you and ask what you should do

E. Just keep track of what they pay and believe they will pay you back eventually

31. Imagine that one of your roommates has a severe shopping problem and $\mathrm{s} /$ he has not been able to pay rent on time. One day, you saw him/her getting back from Bloomingdale's and carrying 20 huge shopping bags despite s/he having told you s/he wouldn't do that anymore and would use the money to pay rent. What would you most likely do? What would you least likely do?

A. Help your roommate work through his/her shopping problem

B. Call a friend or family member to help you think this through

C. Tell yourself that you both can get a handle on it because you made it past other problems

D. Collect yourself and calmly as possible tell your roommate how upset you are

E. Tell yourself that your roommate will get through this with your support

32. You have always had trouble with relationships. Since your teenage years your romantic relationships have failed repeatedly even though you have tried very hard to make them work. Finally, you met the right person and committed yourself to her/him. However, one day, you walked in on your partner cheating on you. What would you most likely do? What would you least likely do?

A. Fight with your partner

B. Tell yourself that your relationship is worth saving and find a way to forgive her/him

C. Concentrate all your energy and time on work so that you don't have to think about it

D. Break up immediately

E. Tell yourself that you will never find love and swear off relationships from now on

F. Tell yourself that you can get past this because you've dealt with heartbreak before

33. You've gotten a summer internship at your dad's company. After a few weeks, several people in your office start needling you and spreading rumors that you got the internship only 
because your dad owns the company, not because of your work and resume. What would you most likely do? What would you least likely do?

A. Confront your coworkers that you don't like being needled and the rumors are not true

B. Channel your emotion to journaling, singing, playing music etc.

C. Start needling back with little things about the coworkers to get them to stop

D. Vent to your family

E. Tell yourself that you can do an excellent job to get your coworkers to stop the rumors

34. Imagine that you were applying for an undergraduate research grant to support your honors thesis project. Applicants are required to prepare a one-page proposal that describes their research objectives and allocations of the fund. After talking to several potential applicants, you were convinced that yours would be the best. However, another student's proposal was selected to receive the grant. What would you most likely do? What would you least likely do?

A. Get a meeting with the grant committee privately to convince them to change their minds

B. Shrug it off; there will be other opportunities to shine

C. Look for another research grant where your talent will be recognized

D. Try to win the support of the other applicants whose proposals were not selected

E. Ask the grant committee to help you understand why the winning proposal was the best

35. Imagine that you have been planning a trip to study abroad. You are checking in at the airport for an international flight. After waiting in a long line, you realize that you forgot to renew your passport. Unable to fly overseas without a renewed passport, you would lose nearly $\$ 10,000$ on the flight tickets, booked hotels, and prepaid tuition and fees. What would you most likely do? What would you least likely do?

A. Change your flight to a destination you can get to since your heart is set on traveling

B. Go home and call a friend or family member to vent your frustration

C. Remind yourself that you are good at negotiation and can get most of the money back

D. Tell yourself that everything happens for a reason and something good will happen next

E. Blame yourself and start crying over lost money

36. You find yourself in the middle of a semester swamped with work. You have 2 papers and 5 chapters that need to be read in the next week. You've been missing social events with friends and family and you have household chores that have been neglected for too long. What would you most likely do? What would you least likely do?

A. Skim the chapters, type a paper good enough for an average grade, and take personal time

B. Feel upset that you're missing out on family/social opportunities

C. Try to get assistance from a friend or classmate

D. Tell yourself that you'll have enough time for everything

E. Remind yourself of a time when you couldn't get everything done and start self-doubting

37. You took on an ambitious course load and you are falling behind in your work. Work and social life is proving to be a distraction and mid-term exams are approaching. Every time you've felt like you've made head way in your assignments more drop into your lap. The deadline to withdraw from classes without a penalty is approaching and you are weighing your options. What would you most likely do? What would you least likely do?

A. Feel that the coming months will be the same or worse 
B. Ask advice from your family or friends to help with the decision

C. Put your social life on hold and decrease your work hours to concentrate on school

D. Remind yourself of what the first half semester was like and doubt you can do any better

E. Make a decision to withdraw from the course with the most work

38. After the first few weeks of the semester your professor announced that he/she would be moving an exam date due to scheduling issues. This new exam date is a week from now and requires diligent studying to understand a few uncovered topics. However, this new exam date falls on the same date as an exam in one of your hardest courses. What would you most likely do? What would you least likely do?

A. Tell yourself that you have the ability to handle this situation

B. Tell you yourself that at least my other classes are easier

C. Speak with a friend who did something similar last semester

D. Anticipate that it is impossible to accomplish and you will get an $\mathrm{F}$ on at least one exam

E. Watch motivation videos to pump you up for this challenge

39. After copious amounts of studying, you decide that the course you are taking is too difficult to comprehend. Thus, you schedule a visit during your professor's office hours to enlist his/her help in understanding the material. However, the professor has changed their office hours and it conflicts with another class that you must be present for. What would you most likely do? What would you least likely do?

A. I do not know how to fix this situation

B. Hope your professor will be able to accommodate your schedule

C. Ask your roommate who has perfect notes for this course

D. Speak with the professor of both courses and explain your situation

E. Call your loved ones to talk about the stress you are experiencing

40. Imagine that you are playing in the intramural tournament finals. It is almost the end of the game. Your team is down but not out. One of your star teammates has gotten injured on a foul play. What would you most likely do? What would you least likely do?

A. Curse at the referee and demand the opponent get ejected

B. Accept that the foul was called and continue playing

C. Go after the player who injured your teammate

D. Realize that your team has overcome adversity before, and will do it again

E. Give up because, without this teammate, you will not win 


\section{Appendix B:}

\section{Coding Scheme}

\section{Adaptability}

Definition: "the ability to successfully adjust to changing circumstances and new situations" (DeSimone et al., 2016, p. 7). We consider both behavioral and cognitive aspects.

\section{A) Behavioral component.}

1) Problem-focused coping: "attempts to remove the obstacle or to minimize its impact" (John, Robins, \& Pervin, 2008, p. 736)

2) Behavioral self-regulation: "making good decisions/thinking things through before acting, impulse control, planfulness, self-discipline, and self-observation" (McLarnon \& Rothstein, 2013)

Note: if items include revenge and retaliation, then code it as adaptability.

A.1) Active coping. Definition: "the process of taking active steps to try to remove or circumvent the stressor or to ameliorate its effects"; active coping includes "initiating direct action, increasing one's efforts, and trying to execute a coping attempt in stepwise fashion" (Carver, Scheier, \& Weintraub, 1989, p. 268). Examples include: "I take direct action to get around the problem," "I concentrate my efforts on doing something about it," "I do what has to be done, one step at a time" (See the COPE scales; Carver et al., 1989).

A.2) Planning. Definition: "thinking about how to cope with a stressor, coming up with action strategies, thinking about what steps to take and how best handle the problem" (Carver et al., 1989, p. 268). Examples include: "I make a plan of action," "I think about how I might best handle the problem," "I think hard about what steps to take," and "I try to come up with a strategy about what to do" (See the COPE scales; Carver et al., 1989).

B) Cognitive flexibility. See Table 2 in Pangallo et al. (2015).

1) Willingness to compromise, accommodate, and consider others' perspectives (McLarnon \& Rothstein, 2013, p. 66). Examples include "am open to change" (DeSimone et al., 2016).

2) Positive acceptance of change. Examples include "I learn to live with it," "I accept the reality of the fact that it happened," "I accept that this has happened and that it can't be changed," and "I get used to the idea that it happened" (See the COPE scales; Carver et al., 1989).

\section{Emotion Regulation}

Definition: "the ability to maintain control over one's emotional reactions and not allow emotion to inappropriately affect decision making" (DeSimone et al., 2016, p. 7). Examples 
include "can control my emotions" and "get overwhelmed by my emotions" (DeSimone et al., 2016, p. 7).

A) Emotion-focused coping. Definition: "attempts to reduce the distress emotions caused by the obstacle (either by reappraisal of the obstacle or management of the emotion" (John et al., 2008, p. 736); "efforts to palliate negative emotions surrounding the situation" (Stanton, Kirk, Cameron, \& Danoff-Burg, 2000, p. 1150). Examples include controlling and regulating emotions, emotion-based decision making, analyzing one's emotions, rumination, self-awareness of one's emotion, and acknowledge of one's emotion.

A.1) Emotional processing. Definition: "active attempting to explore meanings and come to an understanding of one's emotions" (Stanton et al., 2000, p. 1151). Examples include "I take time to figure out what I'm really feeling," "I delve into my feelings to get a through understanding of them," "I realize that my feelings are valid and important," and "I acknowledge my emotions" (See Stanton et al., 2000, p. 1154).

A.2) Emotional expression. Emotion expression takes on both 1) interpersonal (expressing emotion) and 2) intrapersonal (journaling, singing, composing music, etc.) forms. Examples include "I let my feelings come out freely," "I take time to express my emotions," "I allow myself to express my emotions," and "I feel free to express my emotions" (See Stanton et al., 2000, pp. 1151, 1154).

Note: 1) lashing out at somebody is coded as emotional expression; 2) emotion-based decision-making is coded as emotional expression: if the action is to express the feelings, like revenge, that falls under emotion regulation rather than adaptability.

B) Avoidant coping. Definition: "a class of responses that appear to be aimed either at avoiding any acknowledgement that the problem exists (via, e.g., self-distraction, denial, substance use, wishful thinking) or at giving up the attempt to do anything about the problem (via, e.g., substance use, or giving up goals that are being interfered with)" (John et al., 2008, p. 736). Examples include withdrawal, giving-up, denial, self-indulgent escapism — such as sleeping, eating, binge-watching tv/movie, drinking, using recreational drugs, gambling, etc. (John et al., 2008, p. 736) and "I give up the attempt to get what I want" (See Stanton et al., 2000, p. 1154).

Note: to differentiate avoidant coping from adaptability, we consider avoidant coping as giving up any attempt, or giving up the goals, whereas adaptability involves persisting with the goals by switching directions.

C) Spiritual coping. Definition: seeking religion for guidance and comfort. Examples include "Sometimes fate or God can help" (Connor \& Davidson, 2003), "I put my trust in God or my spiritual beliefs," "I pray more than usual," and "I seek God's help" (See the COPE scales; Carver et al., 1989).

\section{Optimism}

Definition: the opposite of pessimism; "the ability to see the positive side of a situation and anticipate good things occurring in the future" (DeSimone et al., 2016, p. 7). Examples 
include positive framing/outlook on things, put new perspective on adversities, look on the bright side, and view change/stress as challenge/opportunity.

\section{Self-efficacy}

Definition: "the belief that one can handle difficult situations and succeed in one's endeavors" (DeSimone et al., 2016, p. 7). Examples include "past success gives confidence for new challenge," "I like challenges," and "I can get through difficult times because I've experiences difficulty before" (Connor \& Davidson, 2003; Wagnild \& Young, 1993)

Note: to differentiate self-efficacy from optimism, self-efficacy emphasizes the belief in one's ability to handle the situation (e.g., "recall...I am able to handle it", whereas optimism focuses on the overall outlook (e.g., "things will pick up").

\section{Social Support}

Definition: "the ability to form supportive relationships and feel comfortable interacting with others" (DeSimone et al., 2016, p. 7); examples include "make friends easily." When coding, 1) focus on the fact that you are already having a relationship with the person or trying to establish one, 2) exclude people (who you don't know) whose jobs are to solve those problems (such as police, plumber, firefighters, security, etc.). There are 5 types of social support (Schaefer, Coyne, \& Lazarus, 1981).

A) Network support. Definition: "communications that affirms individuals' belonging to a network or reminds them of support available from the network" (Mattson \& Gibb-Hall, 2011, p. 186); examples include support group for some mental/physical illness or life changing events.

B) Tangible/instrumental support. Definition: aid in labor, money, time; examples include talking to someone who could do something concrete about the problem (such as dealing with a difficult customer at the restaurant and asking your manager for help).

C) Informational support. Information support is related to suggestions, advice, and information. Examples include seeking advice from someone what to do, and asking someone who has had similar experiences.

Note: going online to ask other people for advice falls under informational support, and going online to search for information is coded as adaptability.

D) Esteem support. Definition: seek reassurance, affirmation, and information for selfevaluation, from other people; it is to boost people's self-esteem/beliefs in their ability to handle a problem.

E) Emotional support. Emotional support entails focusing on emotions and venting (to somebody who is not your supervisor). Examples include venting to friends, talking about my feelings to someone, and "I talk to someone about how I feel" (See Stanton et al., 2000, p. 1154). 


\section{Appendix C:}

\section{Positive and Negative Affect Schedule}

This scale consists of a number of words that describe different feelings and emotions. Read each item and then mark the appropriate answer in the space next to that word. Indicate to what extent you have felt this way during the past few weeks.
1. Interested
11. Irritable
2. Distressed
12. Alert
3. Excited
13. Ashamed
4. Upset
14. Inspired
5. Strong
15. Nervous
6. Guilty
16. Determined
7. Scared
17. Attentive
8. Hostile
18. Jittery
9. Enthusiastic
19. Active
10. Proud
20. Afraid

Note. Each item is rated on a 5-point scale where $1=$ Very slightly or not at all, $2=A$ little, $3=$ Moderately, $4=$ Quite a bit, and $5=$ Extremely. 
Appendix D:

Dispositional Resilience Scale - 15

Copyright (C) by Paul T. Bartone, 2005-2014; all rights reserved. See www.kbmetrics.com for permission for use. 


\section{Appendix E:}

Connor-Davidson Resilience Scale 25

Copyright (C) 2001, 2013, 2015 by Kathryn M. Connor, M.D., and Jonathan R.T. Davidson. M.D.; all rights reserved. See www.connordavidson-resiliencescale.com for permission for use. 


\section{Appendix F:}

\section{Five-by-Five Resilience Scale}

Please use the rating scale below to describe how accurately each statement describes you. Describe yourself as you generally are now, not as you wish to be in the future. Indicate your answer in the response column.

1. Can switch gears easily.

2. Am open to change.

3. Don't like the idea of change.

4. Adapt easily to new situations.

5. Dislike the unknown.

6. Experience my emotions intensely.

7. Am not easily affected by my emotions.

8. Keep my emotions under control.

9. Am very sensitive and easily hurt.

10. Get overwhelmed by emotions.

11. See difficulties everywhere.

12. Expect things to fail.

13. Look at the bright side of life.

14. Fear for the worst.

15. Have a dark outlook on the future.

16. Am good at analyzing problems.

17. Can handle complex problems.

18. Am less capable than most people.

19. Excel in what I do.

20. Can tackle anything.

21. Make friends easily.

22. Feel empty in my relationships.

23. Tend to find social situations confusing.

24. Feel comfortable around people.

25 . Feel isolated from other people.

Note. Each item is rated on a 5 -point scale where $1=$ Very inaccurate, $2=$ Moderately inaccurate, $3=$ Neither inaccurate nor accurate, $4=$ Moderately accurate, and $5=$ Very Accurate. 


\section{Appendix G:}

\section{Depression Anxiety Stress Scales - 21}

Please read each statement and circle a number $0,1,2$ or 3 that indicates how much the statement applied to you over the past week. There are no right or wrong answers. Do not spend too much time on any statement.

1. I found it hard to wind down

2. I was aware of dryness of my mouth

3. I couldn't seem to experience any positive feeling at all

4. I experienced breathing difficulty (e.g., excessively rapid breathing, breathlessness in the absence of physical exertion)

5. I found it difficult to work up the initiative to do things

6. I tended to over-react to situations

7. I experienced trembling (e.g., in the hands)

8. I felt that I was using a lot of nervous energy

9. I was worried about situations in which I might panic and make a fool of myself

10. I felt that I had nothing to look forward to

11. I found myself getting agitated

12. I found it difficult to relax

13. I felt down-hearted and blue

14. I was intolerant of anything that kept me from getting on with what I was doing

15. I felt I was close to panic

16. I was unable to become enthusiastic about anything

17. I felt I wasn't worth much as a person

18. I felt that I was rather touchy

19. I was aware of the action of my heart in the absence of physical exertion (eg, sense of heart rate increase, heart missing a beat)

20. I felt scared without any good reason

21. I felt that life was meaningless

Note. Each item is rated on a 4-point scale where $0=$ Did not apply to me at all, $1=$ Applied to me to some degree, or some of the time, 2 =Applied to me to a considerable degree, or a good part of time, and $3=$ Applied to me very much, or most of the time. 


\section{Appendix H:}

\section{Perceived Quality of Academic Life}

How do you feel about...

1. Your education in college?

2. The classes you are taking in college?

3. What you are learning in college?

4. Your instructors in college?

5. The progress you are making toward your educational goals?

6. How well you are doing in your classes?

Note. Each item is rated on a 7-point scale where $0=$ Terrible, and $6=$ Delighted . 


\section{Appendix I:}

\section{Attention Check}

1. If you are paying attention to the survey right now, click Very Accurate. ${ }^{b}$

2. The sky is blue. ${ }^{\text {a }}$

3. I do not understand a word of English. ${ }^{\text {a }}(\mathrm{R})$

Note. ${ }^{\text {a }}$ Each item is rated on a 5-point scale where $1=$ Strongly disagree, $2=$ Disagree a little, $3=$ Neither agree nor disagree, $4=$ Agree a little, and $5=$ Strongly agree $. \mathrm{R}=\mathrm{item}$ reversed coded (strongly disagree or disagree not selected).

${ }^{\mathrm{b}}$ Item 3 is rated on a on a 5-point scale where $1=$ Very inaccurate, $2=$ Moderately inaccurate, 3 = Neither inaccurate nor accurate, $4=$ Moderately accurate, and $5=$ Very Accurate. 


\section{Appendix J:}

\section{Demographic Questionnaire}

The following questions will give researchers a more complete look at this study. You will be asked some questions about yourself. Your answers are highly appreciated.

1. *What is your age? (years)

2. What is your gender?

o Male

○ Female

$\circ$ Transgender

$\circ$ Other

$\circ$ Prefer not to respond

3. What is your race/ethnicity?

$\circ$ White

○ African American or Black

$\circ$ Asian

- Native Hawaiian or Other Pacific Islander

- American Indian or Alaska Native

o Multiracial

○ Hispanic/Latino

$\circ$ Prefer not to respond

4. What is your highest level of attained education?

o Grade school

○ High school graduate, or GED

o Some college, no degree

- Associate degree

- College graduate

$\circ$ Post-graduate training

5. What is your current relationship status?

o Single

$\circ$ In a relationship

○ Married

- Cohabitating (living together)

o Separated

$\circ$ Divorced

$\circ$ Widowed

$\circ$ Other; *please specify

6. *What is your religious belief?

7. What is your current academic status?

o Freshman 
o Sophomore
o Junior
o Senior
o Other; *please specify

8. *What is your cumulative grade-point-average (GPA)?

9. *How many hours do you work per week?

Note. * indicates that the question is open-ended. 


\section{Appendix K:}

\section{IRB Approval}

\section{USF \\ UNIVERSITY OF \\ SOUTH FLORIDA}

November 22, 2016

Yuejia Teng

Psychology

Tampa, FL 33647
RESEARCH INTEGRITY AND COMPLIANCE

Institutional Review Boards, FWA No. 00001669

12901 Bruce B. Downs Blvd., MDC035 • Tampa, FL $33612-4799$

(813) $974-5638$ • FAX (813) $974-7091$

\section{RE: Exempt Certification}

IRB\#: Pro00028701

Title: Development and Validation of a Situational Judgment Test of Resilience--Study 2

Dear Yuejia Teng:

On 11/22/2016, the Institutional Review Board (IRB) determined that your research meets criteria for exemption from the federal regulations as outlined by 45CFR46.101(b):

(2) Research involving the use of educational tests (cognitive, diagnostic, aptitude, achievement), survey procedures, interview procedures or observation of public behavior, unless:

(i) information obtained is recorded in such a manner that human subjects can be identified, directly or through identifiers linked to the subjects; and (ii) any disclosure of the human subjects' responses outside the research could reasonably place the subjects at risk of criminal or civil liability or be damaging to the subjects' financial standing, employability, or reputation.

As the principal investigator for this study, it is your responsibility to ensure that this research is conducted as outlined in your application and consistent with the ethical principles outlined in the Belmont Report and with USF HRPP policies and procedures.

Please note, as per USF HRPP Policy, once the Exempt determination is made, the application is closed in ARC. Any proposed or anticipated changes to the study design that was previously declared exempt from IRB review must be submitted to the IRB as a new study prior to initiation of the change. However, administrative changes, including changes in research personnel, do not warrant an amendment or new application.

Given the determination of exemption, this application is being closed in ARC. This does not limit your ability to conduct your research project.

We appreciate your dedication to the ethical conduct of human subject research at the University of South Florida and your continued commitment to human research protections. If you have any questions regarding this matter, please call 813-974-5638. 
Sincerely,

$\operatorname{ram}($ Thimke, P.I.

John Schinka, Ph.D., Chairperson

USF Institutional Review Board 